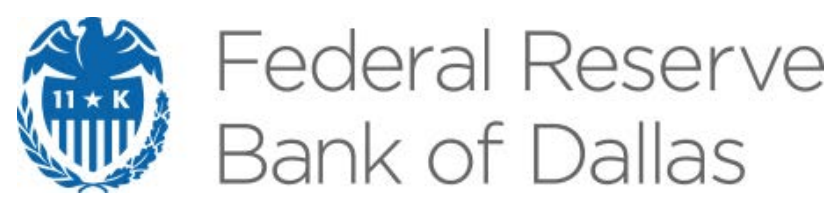

\title{
Monetary Policy Spillovers, Capital Controls and Exchange Rate Flexibility, and the Financial Channel of Exchange Rates
}

Georgios Georgiadis and Feng Zhu

Globalization Institute Working Paper 363

Research Department

https://doi.org/10.24149/gwp363

Working papers from the Federal Reserve Bank of Dallas are preliminary drafts circulated for professional comment. The views in this paper are those of the authors and do not necessarily reflect the views of the Federal Reserve Bank of Dallas or the Federal Reserve System. Any errors or omissions are the responsibility of the authors. 


\title{
Monetary Policy Spillovers, Capital Controls and Exchange Rate Flexibility, and the Financial Channel of Exchange Rates*
}

\author{
Georgios Georgiadis $^{\dagger}$ and Feng $\mathrm{Zhu}^{\ddagger}$
}

May 5, 2019

\begin{abstract}
We assess the empirical validity of the trilemma (or impossible trinity) in the 2000 s for a large sample of advanced and emerging market economies. To do so, we estimate Taylorrule type monetary policy reaction functions, relating the local policy rate to real-time forecasts of domestic fundamentals, global variables, as well as the base-country policy rate. In the regressions, we explore variations in the sensitivity of local to base-country policy rates across different degrees of exchange rate flexibility and capital controls. We find that the data are in general consistent with the predictions from the trilemma: Both exchange rate flexibility and capital controls reduce the sensitivity of local to base-country policy rates. However, we also find evidence that is consistent with the notion that the financial channel of exchange rates highlighted in recent work reduces the extent to which local policymakers decide to exploit the monetary autonomy in principle granted by flexible exchange rates in specific circumstances: The sensitivity of local to base-country policy rates for an economy with a flexible exchange rate is stronger when it exhibits negative foreign-currency exposures which stem from portfolio debt and bank liabilities on its external balance sheet and when base-country monetary policy is tightened. The intuition underlying this finding is that it may be optimal for local monetary policy to mimic the tightening of base-country monetary policy and thereby mute exchange rate variation because a depreciation of the local currency would raise the cost of servicing and rolling over foreign-currency debt and bank loans, possibly up to a point at which financial stability is put at risk.
\end{abstract}

Keywords: Trilemma, financial globalization, monetary policy autonomy, spillovers

JEL Classifications: F42, E52, C50

\footnotetext{
*We would like to thank, without implicating, Jan-Christoph Ruelke and Eduardo Levy-Yeyati for sharing their data with us as well as Menzie Chinn, Stefan Eichler, Johannes Gräb, Sebastian Kripfganz, Samuel Ligonniere, Gianni Lombardo, Gernot Müller, Dominic Quint, llhyock Shim, and James Yetman, as well as seminar and conference participants at the BIS, ECB, DIW Berlin, National Bank of Serbia, Reserve Bank of India, the Central Bank of the Republic of Turkey conference on "Changing Economic Landscape and Policy Implications for Emerging Economies," the LEM/CNRS/University of Lille/GdRe workshop "International Finance: Do Exchange Rates Still Matter?," and the 8th IWH/INFER workshop "International Capital Flows and Macroprudential Stability" for helpful discussions and suggestions. Adam Cap provided outstanding research assistance. This paper was partly written while Georgios Georgiadis was visiting the BIS under its Central Bank Research Fellowship program. The views expressed in the paper are those of the authors and do not necessarily reflect those of the BIS, the ECB, the Eurosystem, the Federal Reserve Bank of Dallas or the Federal Reserve System and should not be reported as such.

${ }^{\dagger}$ Georgios Georgiadis, European Central Bank, georgios.georgiadis@ecb.int.

${ }^{\ddagger}$ Feng Zhu, Bank for International Settlements, feng.zhu@bis.org.
} 


\section{Introduction}

The trilemma is a cornerstone of international macroeconomics and provides clear and concrete recommendations for policymakers. Several important contributions have been concerned with subjecting the trilemma hypothesis to the data, indeed finding evidence that is consistent with its predictions. ${ }^{1}$ Most importantly, the findings in this literature suggest that both restricting capital account openness and flexible exchange rates enhance monetary policy autonomy. However, the empirical validity of the trilemma has been contested recently. In particular, a different strand of the literature has documented that a powerful global financial cycle is driving financial conditions also in economies with flexible exchange rates. Against this background, it has been argued that the global financial cycle inhibits the transmission of local monetary policy to local financial conditions - and hence the control of macroeconomic fundamentals - even in economies with flexible exchange rates. Importantly, it is argued that a corollary of these findings is that restricting capital account openness but not flexible exchange rates are necessary and sufficient to ensure local monetary policy autonomy. Hence the claim that the trilemma has morphed into a dilemma.

In this paper we consider a different reason why the potential of flexible exchange rates to grant monetary policy autonomy might have been reduced recently. A key role in the mechanism we consider is assumed by the "financial channel of exchange rates" that is being studied in a growing body of work. In particular, the rise of financial globalisation has not only been associated with an increase in cross-border gross but also currency exposures. In such an environment, when the local currency appreciates in response to an easing of base-country monetary policy, local borrowers' balance sheets that are subject to currency mismatches due to cross-border borrowing appear stronger, resulting in lower perceived credit risk and increased perceived borrowing capacity, ultimately setting in motion a feedback loop in which loose base-country monetary policy is transmitted to local financial conditions. In turn, when the local currency depreciates in response to a tightening of base-country monetary policy, the feedback loop is reversed and local financial conditions are tightened, possibly even putting at risk financial stability. Thus, instead of insulating local financial conditions from basecountry monetary policy, in the presence of foreign-currency exposures flexible exchange rates might in fact amplify spillovers from base-country monetary policy. To the extent that these spillovers lead to a build of vulnerabilities that may put at risk financial stability when the tide turns, local monetary policy may find it optimal to reduce exchange rate variation in order to prevent the financial channel of exchange rates to play out. To do so, local monetary policy may purposely choose to mimic base-country monetary policy regardless of the stage of the business cycle also in economies for which flexible exchange rates in principle confer monetary policy autonomy.

To summarise, in the presence of foreign-currency exposures it may be optimal for local monetary policy to not exploit the policy space in principle granted by flexible exchange rates and to instead avoid exchange rate variation by mimicking base-country monetary policy. The reason for the reluctance of local monetary policy to deviate from the base-country monetary

\footnotetext{
${ }^{1}$ We discuss the relevant literature in detail in Section 2.
} 
policy stance in this environment is that exchange rate variation amplifies the spillovers from base-country monetary policy in the presence of foreign-currency exposures, possibly to a degree which puts at risk local financial stability; this argument is spelled out in detail in Diamond et al. (2018). It is important to emphasise that this mechanism implying a reduced potential of exchange rate flexibility to grant monetary policy autonomy is different from that put forth in the literature on the global financial cycle and the trilemma/dilemma debate. Specifically, in the latter the trilemma is argued to have morphed into a dilemma because local monetary policy does not transmit to local financial conditions in economies with flexible exchange rates due to the reach of the global financial cycle. In contrast, the mechanism in this paper is concerned with the possibility that local monetary policy may find it optimal to not deviate from base-country monetary policy in the first place, and hence to not exploit the policy space granted by exchange rate flexibility. ${ }^{2}$ In this paper, we confront predictions from this hypothesis with the data. The key mechanism that we explore in the paper thus echoes earlier discussions in the literature about "fear-of-floating", parsed into the context of the trilemma/dilemma debate on the potential of flexible exchange rates to bolster monetary policy autonomy.

Our results document that the trilemma is well and alive in the sense that both restrictions on capital account openness and exchange rate flexibility in general reduce the spillovers from base-country to local monetary policy, thereby strengthening local monetary policy autonomy. Our results are thus inconsistent with the hypothesis that the trilemma has morphed into a dilemma. However, we also find evidence that is consistent with the hypothesis that the financial channel of exchange rates reduces the extent to which local policymakers exploit the monetary autonomy in principle granted by flexible exchange rates in specific circumstances: The sensitivity of local to base-country monetary policy is stronger for an economy with flexible exchange rates the larger its foreign-currency exposure, that is the more the economy is net short in foreign currency on its external balance sheet. We furthermore document that the data are consistent with additional, more refined predictions of the financial channel of exchange rates in the context of local monetary policy autonomy in the presence of foreigncurrency exposures. Specifically, we find that the sensitivity of local to base-country monetary policy is reduced by more when the foreign-currency exposure is improved by reducing net short positions rather than by increasing net long positions; that the sensitivity of local to base-country monetary policy is stronger if the foreign-currency exposure stems from portfolio debt instruments or bank loans rather than from more resilient foreign direct investment and portfolio equity instruments with state-contingent payoffs and longer investment horizons; and that the sensitivity of local to base-country monetary policy is stronger when the latter is tightened rather than loosened, consistent with the prediction that local policymakers are particularly concerned about local currency depreciation under which borrowing constraints may become binding in the presence of foreign-currency exposures.

We obtain these findings by estimating Taylor-rule-type monetary policy reaction functions

\footnotetext{
${ }^{2}$ Another possible policy aimed at reducing exchange rate variation is foreign exchange intervention. We do not explore the possible effects of foreign exchange interventions in this paper. However, we discuss in Section 4 that our focus on local economies potentially mimicking base-country policy rates in order to avoid exchange rate fluctuation is not susceptible to bias stemming from omitting foreign exchange intervention from the empirical analysis.
} 
for 47 advanced economies (AEs) and emerging market economies (EMEs) for the time period from January 2002 to December 2018; because we do not consider in our sample the US and the euro area given these are the base countries, our sample is dominated by EMEs. The Taylor-rule arguments we consider are the lagged monetary policy rate, real-time forecasts of GDP growth and inflation, the VIX, global commodity prices, and the base-country monetary policy rate. The inclusion of real-time forecasts and global variables accounts for the possible correlation between local and base-country monetary policy that is due to common shocks. The magnitude of the coefficient on the base-country policy rate in the Taylor rule thus indicates the extent to which local monetary policy follows base-country monetary policy over and above what would be implied by synchronised business cycles, common shocks and macroeconomic spillovers from the former to the latter. We consider fixed effects dynamic panel data regressions estimated separately for samples of economies with different exchange rate flexibility and capital control configurations, namely (i) "limited exchange rate flexibility" and "limited capital controls", (ii) "limited exchange rate flexibility" and "extensive capital controls", (iii) "extensive exchange rate flexibility" and "limited capital controls", as well as (iv) "extensive exchange rate flexibility" and "extensive capital controls". In order to test the predictions from the financial channel of exchange rates in the context of the trilemma we interact the base-country policy rate with various variables reflecting the local economy's foreign-currency exposure. We also document that our findings are robust to a range of alternative specifications of the empirical framework employed, for example regarding the choice of the sample period, cross-country parameter heterogeneity, the dynamic model specification, the time-series properties of the data, the measurement of the stance of monetary policy, and the Taylor-rule specification.

The rest of the paper is organised as follows. Section 2 surveys existing literature. The empirical analysis is carried out in Sections 3 and 4, where we derive our estimation equations, describe the data and present our results on the empirical evidence for the trilemma and the financial channel of exchange rates. Finally, Section 5 concludes.

\section{Existing literature}

This paper is related to and motivated by several strands in the literature. First, the paper is related to the classic literature that studies the empirical validity of the policy trade-offs implied by the trilemma. In particular, Shambaugh (2004) studies a sample of more than 100 economies for the time period from 1973 to 2000, and finds that pegged exchange rate regimes follow base-country interest rates significantly more closely than non-pegged regimes. ${ }^{3}$ Obstfeld et al. (2005) find very similar results with the same methodological framework applied to a sample that spans the time period from 1870 to 2000 for a smaller set of economies. ${ }^{4}$ Klein and Shambaugh (2015) consider a sample of more than 100 advanced and emerging market economies for the time period from 1973 to 2011, finding that not only floats but

\footnotetext{
${ }^{3}$ Frankel et al. (2004) consider a similar econometric framework and obtain similar results for the short-run relationship between foreign and local interest rates.

${ }^{4}$ Also studying historical samples, in a somewhat different context Bekaert and Mehl (2017) as well as Jorda et al. (2017) obtain very similar results.
} 
even soft-pegs enhance monetary policy autonomy; for capital controls, they find that only "walls" rather than "gates", and only extensive rather than limited capital controls enhance monetary policy autonomy. ${ }^{5}$ The general thrust of this series of highly influential papers is to put forth empirical evidence that supports the predictions of the trilemma, in particular as regards the potential of flexible exchange rates for enhancing monetary policy autonomy. Notice that this literature has not claimed that base-country monetary policy does not impact at all local monetary policy in economies with flexible exchange rates, but rather that the effects are weaker compared to economies with less flexible exchange rates. A number of recent studies has confirmed the findings of this strand of the literature, including Obstfeld (2015), Caceres et al. (2016), Kharroubi and Zampolli (2016), Ricci and Shi (2016), Obstfeld et al. (2017), as well as Aizenman et al. (2016).

This paper is also related to the literature arguing that the trilemma has morphed into a dilemma. In particular, Passari and Rey (2015) document for a sample of 53 AEs and EMEs over the time period from 1990 to 2012 that there are no significant differences in the extent to which the global financial cycle affects local financial conditions across economies with different degrees of exchange rate flexibility; Rey (2016) obtains very similar results for the sample of small open, inflation-targeting economies of Canada, Sweden, New Zealand and the UK for data which span the time period from the mid-1980s to 2012. In contrast to the findings for the short end of the yield curve, Obstfeld (2015) finds that the effects of base-country long-term on local long-term rates do not differ across economies with different exchange rate regimes; and Kharroubi and Zampolli (2016) find that the effects of basecountry on local long-term rates are even stronger for economies with extensive exchange rate flexibility. There are also a few studies which test the empirical validity of the trilemma focusing on the monetary policy stance, and put forth evidence that supports the dilemma hypothesis. For example, Hofmann and Takats (2015) consider 30 AEs and EMEs for the time period from 2000 to 2014, and find that the transmission of US to local policy rates is not dampened by flexible exchange rates. Similarly, Han and Wei (2018) examine 28 AEs and EMEs for the time period from 1990 to 2014 and find that flexible exchange rates do not dampen the transmission of a US monetary policy easing to local policy rates.

More importantly, this paper is related to the recent literature that is concerned with the financial channel of the exchange rate. Specifically, Bruno and Shin (2015) build a model in which local banks fund their domestic lending by borrowing from international banks and in which their lending capacity varies with the exchange rate: When the local currency appreciates, local borrowers' balance sheets that are subject to currency mismatch between assets and liabilities appear stronger, resulting in lower credit risk and hence increased borrowing capacity, and possibly a borrowing boom that fuels overheating. Moreover, when the currency depreciates after local borrowers have built up previously cheap foreign-currency

\footnotetext{
${ }^{5}$ Consistent with these findings, Miniane and Rogers (2007) do not find evidence that capital controls dampen the transmission of US monetary policy shocks to local interest rates. Bluedorn and Bowdler (2010) document that economies with flexible exchange rates exhibit smaller interest rate sensitivity to US monetary policy shocks. And di Giovanni and Shambaugh (2008) find that economies with flexible exchange rates exhibit smaller contractions in output in response to a rise in foreign interest rates than economies with fixed exchange rates, and that this is due to a greater sensitivity of local to foreign interest rates in the latter regime; at the same time, the effect of capital controls is estimated considerably less precisely and weaker.
} 
exposures, the boon turns into bane by precipitously disrupting borrowing and possibly even leading to a financial crisis. ${ }^{6}$ Another channel for the global transmission of base-country monetary policy that has been emphasised recently is the "international risk-taking channel" (Bruno and Shin, 2015). The models considered in this context feature risk-neutral leveraged financial intermediaries that are subject to a value-at-risk constraint. In this environment, a shock that lowers measured risk - such as a US monetary policy easing - raises financial intermediaries' demand for assets, which compresses risk premia. In turn, lower risk premia relax further financial intermediaries' value-at-risk constraint, eventually setting in motion a feedback loop. The international risk-taking channel amplifies the financial channel of exchange rates when the initial shock that lowers measured risk is an appreciation of the local exchange rate.

Bruno and Shin (2015) provide empirical evidence in a sample of 46 economies over the time period from 1996 to 2011 documenting that an appreciation of the local currency is followed by expansion of banking inflows. Cerutti et al. (2017) for 77 economies over the time period from 1990 to 2014 as well as Avdjiev et al. (2018) for 34 EMEs over the time period from 2001 to 2016 also provide empirical evidence for the importance of the exchange rate for the transmission of the global financial cycle to local credit supply. Kearns and Patel (2016) document in a sample of 44 economies for the time period from the mid-1990s to 2016 that appreciation of the local debt-weighted effective exchange rate is associated with an acceleration of GDP growth, in contrast to an appreciation of the trade-weighted effective exchange rate. In a sample for 20 EMEs over the time period from 2005 to 2015 Hofmann et al. (2017) document that the financial channel of exchange rates is not confined to the private sector: Appreciation of the local currency vis-à-vis the US dollar compresses risk premia in EME sovereign bond yields. Confirming these findings, Bernoth and Herwartz (2019) additionally find that the compression in sovereign risk premia is more pronounced for economies which are less exposed to US dollar currency mismatches. Kalemli-Ozcan et al. (2018) using firm-level data find that when faced with local currency appreciation against the US dollar firms with larger initial foreign-currency denominated debt increase their leverage more than those with lower initial foreign-currency denominated debt. Using data on loans of US banks to firms in 105 economies, Niepmann and Schmidt-Eisenlohr (2017) document that depreciation of the local currency makes a firm with foreign-currency debt more likely to become past due on its loans than a firm with local-currency debt. Bräuning and Ivashina (2018) document that the effects of US monetary policy easing and tightening on US dollar lending to EME firms is asymmetric, with a tightening leading to an abrupt contraction in credit to borrowing firms in EMEs. Work that relates local exchange rate depreciation to financial crises includes Gourinchas and Obstfeld (2012), who document that exchange rate appreciations are - besides leverage - the most robust and significant predictor of financial crises. And Durdu et al. (2018) document in a historical cross-country sample that spans

\footnotetext{
${ }^{6}$ The financial channel of exchange rates is related to the classic "original sin" in which economies issue debt in foreign currency and in which exchange rate depreciation might lead to financial crises. However, "original sin" has been discussed mainly in the context of less-developed emerging market economies which for institutional reasons can issue debt only in foreign currency. It has also not been related directly to the theme of global liquidity and the global financial cycle. Moreover, original sin has been conceived as an asymmetric risk in terms of the direction of exchange rate movements, as the focus has been on the effects of depreciations of the local currency.
} 
more than 100 years and 69 economies that US monetary policy tightening increases the probability of banking crises in economies with direct linkages to the US, either in the form of stronger trade links or a significant share of US dollar-denominated liabilities.

Finally, this paper is related to a strand of the literature which shows that limiting exchange rate variability may be optimal for monetary policy in the presence of foreign-currency exposures. Cook (2004) constructs a New Keynesian small open-economy DSGE model with a financial accelerator mechanism involving foreign currency debt. In the model, a currency depreciation damages the balance sheets of domestic firms by making foreign-currency debt more expensive to repay, which leads to a contraction in optimal investment that more than offsets expansionary effects through expenditure switching. As monetary expansion has contractionary effects, counter-cyclical monetary policy does not stabilise the economy in the face of business cycle shocks, and hence the stabilisation properties of a fixed exchange rate regime are superior to a set of interest rate rules that target inflation. Choi and Cook (2004) examine a New Keynesian small open-economy DSGE model in which capital flows are intermediated by banks whose cost of capital depends on the state of their balance sheets. An unexpected nominal exchange rate depreciation negatively affects bank balance sheets, increases the country's default-risk premium and offsets the expansionary effects of expenditure switching. Because a rise in the default-risk premium also induces a temporary depreciation, the model features a powerful feedback loop between bank foreign-currency exposures, the default-risk premium, and a floating exchange rate. Due to the presence of this mechanism, Choi and Cook (2004) find that fixed exchange rates provide greater macroeconomic stability than floating exchange rates in the presence of foreign-currency exposures. Elekdag and Tchakarov (2007) evaluate the welfare implications of fixed and flexible exchange rate regimes in a New Keynesian small open-economy DSGE model that incorporates a financial accelerator with liability dollarisation. They identify leverage and debt-to-GDP ratios above which an exchange rate peg is welfare superior to a flexible exchange rate regime. The results indicate that EMEs with even moderate levels of debt denominated in foreign currency may find it beneficial to stabilise their exchange rates. In a somewhat different context, Rappoport (2009) assesses the motives behind domestic dollarisation. Specifically, because devaluations occur more frequently during recessions, dollar assets provide insurance in economies with incomplete financial markets as a devaluation increases the home-currency value of dollar assets. Examining the interaction between the currency composition of foreign debt and the optimal devaluation response of the central bank to aggregate shocks, the paper finds that in some of the multiple equilibria optimal monetary policy minimises exchange rate fluctuations in the presence of a high degree of dollarisation. ${ }^{7}$

\footnotetext{
${ }^{7}$ Although they do not study optimal monetary policy, Cavallino and Sandri (2018) show that in a structural model the presence of foreign-currency mismatches a tightening of global financial conditions — driven, for example, by a tightening of base-country monetary policy — may be mitigated only by an analogous tightening of local monetary policy in economies with flexible exchange rates.
} 


\section{Assessing the empirical validity of the trilemma}

\subsection{Empirical framework}

We estimate Taylor-rule type monetary policy reactions functions in order to assess the sensitivity of local to base-country policy rates. Specifically, we consider

$$
i_{i t}^{p}=\chi_{i}+\rho_{i} i_{i, t-1}^{p}+\left(1-\rho_{i}\right)\left(\boldsymbol{\phi}_{i}^{\prime} \boldsymbol{x}_{i t}^{e}+\boldsymbol{\kappa}_{i}^{\prime} \boldsymbol{z}_{t}+\alpha_{i} i_{b_{i}, t}^{p}\right)+\nu_{i t},
$$

where $i_{i t}^{p}$ is the local policy rate, $\boldsymbol{x}_{i t}^{e}$ includes (real-time) forecasts of local fundamentals, $\boldsymbol{z}_{t}$ is a set of global variables, and $i_{b_{i}, t}^{p}$ is the policy rate of the local economy $i$ 's base-country $b_{i}$. By considering a Taylor-rule type monetary policy reactions function we do not mean to claim that monetary policy is in actuality carried out based on such a rule, but rather that it is a useful approximation of the way monetary policy is in fact calibrated (Clarida et al., 1998, 2000). The trilemma predicts that the sensitivity of the local economy's policy rate to that of the base-country reflected by $\alpha_{i}$ is a function of the former's exchange rate regime and its capital account openness. Specifically, the textbook version of the trilemma predicts that for the regimes with an open capital account and a fixed exchange rate (I), a closed capital account and a fixed exchange rate (II), an open capital account and a flexible exchange rate (III), as well as a closed capital account and a flexible exchange rate (IV), we have

$$
H_{0}: \quad \alpha_{I}=1, \alpha_{I I}=\alpha_{I I I}=\alpha_{I V}=0 .
$$

However, in reality there are few cases of these "corner" solutions, and intermediate cases of capital account openness and exchange rate regimes are the rule. ${ }^{8}$ Hence, we consider a more pragmatic set of regimes (see Klein and Shambaugh, 2015), namely regimes with "limited capital controls" and "limited exchange rate flexibility" (I), "extensive capital controls" and "limited exchange rate flexibility" (II), "limited capital controls" and "extensive exchange rate flexibility" (III), as well as "extensive capital controls" and "extensive exchange rate flexibility" (IV). Accordingly, the more realistic trilemma predictions are

$$
H_{0}: \quad \alpha_{I}>\alpha_{I I}, \alpha_{I I I}>\alpha_{I V} \geq 0 .
$$

We confront these predictions from the trilemma with the data by estimating a modified version of Equation (1), namely

$$
i_{i t}^{p}=\chi_{i j}+\rho_{j} i_{i, t-1}^{p}+\left(1-\rho_{j}\right)\left(\phi_{j}^{\prime} \boldsymbol{x}_{i t}^{e}+\boldsymbol{\kappa}_{j}^{\prime} \boldsymbol{z}_{t}+\alpha_{j} i_{b_{i}, t}^{p}\right)+\nu_{i t} .
$$

In particular, notice that relative to the country-specific Taylor rules in Equation (1), Equation (4) is a dynamic fixed-effects panel data regression model that assumes homogeneity of coefficients for economies that are in the same regime $j \in\{I, I I, I I I, I V\}$. The homogeneity assumption is not only imposed on the sensitivity of the local to the base-country policy rate, but on all slope coefficients. We relax the assumption of coefficient homogeneity across

\footnotetext{
${ }^{8}$ See Aizenman et al. (2013) for a documentation of the empirical relevance of "middle-ground" policy choices. See also the discussion about credible target zones in Obstfeld et al. (2005).
} 
economies within a given regime in robustness checks below.

Notice several additional remarks on the econometrics underlying the estimation of Equation (4). First, as we describe in the next section, the panel data setting in this paper is one in which $T$ is large. This implies that in contrast to the traditional large- $N /$ small- $T$ setting the Nickell-bias - typically addressed by using GMM estimators — will be very small (Judson and Owen, 1999). Second, the Taylor rule in Equation (4) can be interpreted as an errorcorrection model. Then, if at least some of the variables are non-stationary, the corresponding equilibrium relationship is a co-integrating relationship; and if all variables are stationary, the equilibrium relationship is a long-run levels relationship. Importantly, if such an equilibrium relationship exists, then inference about the estimates of $\boldsymbol{\phi}_{j}, \boldsymbol{\kappa}_{j}$, and $\alpha_{j}$ is standard, regardless of whether the variables are non-stationary or stationary (Pesaran and Shin, 1999). Third, we could in principle test for the existence of such an equilibrium relationship at the country level, even without knowledge of the orders of integration of the variables involved (Pesaran et al., 2001). However, we have a very strong prior that such an equilibrium relationship exists, as local monetary policy is almost surely determined either by forecasts of local fundamentals, global variables, or by base-country policy rates. Moreover, while the corresponding tests have been worked out for the time-series setting at the country level, they are not available for the panel context. One could then argue to resort to panel co-integration analysis, which is however known to be rather sensitive to the assumptions on cross-country heterogeneity under the null and alternative hypotheses. We thus proceed assuming that there exists an equilibrium relationship without carrying out formal tests at the country or panel level. We explore the robustness of our findings to considering only those cases in which we can reject the null of no long-run levels relationship at the country level in Appendix E.

\subsection{Data and definition of variables}

\subsubsection{Sample period and economies included}

We consider a sample of monthly data for $47 \mathrm{AE}$ and EMEs for the time period from January 2002 to December 2018. Importantly, we drop the time period from July 2007 to December 2009 in order to preclude that our estimates might be unduly driven by events related to the global financial crisis. In robustness checks in Appendix E, we explore alternative sample periods, the results from samples that include the time period from July 2007 to December 2009 , and from recursively varying samples. The set of economies included in the sample is listed in Table 1 and is determined by data availability, in particular for the data on real-time forecasts from Consensus Economics (CE, see below). All country-specific data we consider in the estimation are plotted in Figures 4 to 8 in Appendix D. We do not include the US and the euro area in our sample, given that these are the two base-countries we consider. ${ }^{9}$ As a

\footnotetext{
${ }^{9}$ Considering the US and the euro area as base-countries is consistent with Shambaugh (2004), except for two cases: In Shambaugh (2004) Australia is the base-country of New Zealand, and Malaysia is the basecountry of Singapore. We believe that for the purposes of this paper and the time period we investigate it is more plausible to consider only the US and the euro area as base-countries.
} 
result from not including individual euro area countries, our country sample is dominated by EMEs.

\subsubsection{Real activity and inflation expectations}

For the real-time forecasts of inflation and real activity in $\boldsymbol{x}_{i t}^{e}$ in Equation (4) we would ideally use actual central bank projections. However, many central banks do not publish their projections at all. Moreover, among those central banks which do publish their projections, many produce projections only a few times per year. ${ }^{10}$ For these reasons, instead of considering actual central bank projections, we use for $\boldsymbol{x}_{i t}^{e}$ in Equation (4) data on real-time forecasts from CE. In particular, CE gathers forecasts of private banks and other financial institutions for more than 1,000 variables from over 85 AEs and EMEs in Europe, the Asia Pacific region and Latin America. Incoming survey responses are processed using proprietary software and checked for accuracy, completeness and integrity. CE forecasts are generally available for all 12 months in a year since 1990 for AEs, Latin American and Asian EMEs, but only since 2008 for Eastern European EMEs. ${ }^{11}$ In Appendix C we document that CE real-time forecasts are closely related to publicly available, actual central bank projections. ${ }^{12}$ We include twelve-months ahead forecasts of GDP growth and inflation in $\boldsymbol{x}_{i t}^{e}{ }^{13}$ Finally, notice that to the extent that both local and base-country policymakers incorporate the impact of common shocks on the local outlook, the inclusion of real-time forecasts should account for any correlation between local and base-country policy rates that is due to common shocks.

\subsubsection{Additional Taylor-rule arguments}

In the set of global variables $\boldsymbol{z}_{t}$ we include the first difference of the logarithm of global commodity prices and the first-difference of the VIX. The inclusion of these variables may be important to the extent that the inclusion of real-time forecasts of local fundamentals in $\boldsymbol{x}_{i t}^{e}$ does not fully account for the correlation between local and base-country policy rates that is induced by common shocks. In robustness checks in Appendix E we report results from

\footnotetext{
${ }^{10}$ This does not mean that central bank decision-makers are not updating their views on the outlook before monetary policy decision meetings that take place between the projection exercises; typically the projections are updated using a variety of macroeconometric tools as well as anecdotal evidence and judgement. For example, the ECB's macroeconomic projections for the euro area are published just four times a year, namely in March and September when they are produced by ECB staff alone, and in June and December when they are produced jointly by staff of euro area national central banks and the ECB. For the monetary policy decision meetings that take place between the projection exercises, the projections are updated using a variety of macroeconometric tools.

${ }^{11}$ Data for a subset of months in a given year are available since 1991 for Eastern European EMEs. However, the gaps in the time series preclude running panel regressions at the monthly frequency.

${ }^{12}$ Notice that using CE forecast data also has the advantage that we can consider a large number of economies at the monthly frequency. Monthly data on real activity and inflation are typically available only for a smaller set of economies, and there are generally no real-time data available. Moreover, for real activity one would typically consider industrial production, which is not defined identically across economies, and also only reflects a limited share of overall real activity.

${ }^{13}$ One disadvantage of CE data is that they are fixed-event forecasts, that is for example a forecast in month $t$ in year $T$ of GDP growth over year $T+1$. We adopt the approach of Dovern et al. (2012) to transform the CE fixed-event forecasts into fixed-horizon forecasts.
} 
regressions in which we include additional, country-specific variables in the Taylor rule, such as the real effective exchange rate.

\subsubsection{Local and base-country policy rates}

Recall that the question pursued in this paper centers on the correlation between the monetary policy stance in the base-country and the local economy across configurations of capital control and exchange rate flexibility regimes. The emphasis here is on the monetary policy stance, broadly defined. While in normal times the monetary policy stance is reflected well by the conventional policy rate, this is not true anymore when a central bank hits its effective lower bound. In this case, alternative measures may better reflect the overall monetary policy stance. A widely-used statistic in empirical work in this context are shadow rates. Hence, and given that both the Federal Reserve and the ECB hit their effective lower bounds during our sample period, we consider shadow rates for the base-country policy rate. In general, we also consider a shadow rate for the local policy rate in case the local central bank hit the effective lower bound during the sample period we consider.

Unfortunately, while shadow rates are available for the US and the euro area, they are available only for a few of the local economies we consider and which hit their effective lower bound after the global financial crisis; in fact, except for the US and the euro area we only have shadow rates for the UK and Japan. In the cases in which there is no shadow rate for a local economy which hit the effective lower bound, the question is whether it is more appropriate to correlate the shadow rate of the base-country with the conventional policy rate of the local economy, or to correlate the conventional policy rates of the base-country and the local economy. Acknowledging that none of these two options is ideal, in the baseline we use conventional policy rates for both the base-country and the local economy in the few cases in which we do not have a shadow rate for a local economy that hit the effective lower bound. Finally, in the case of local economies with a peg we use conventional policy rates also for the base-country. The rationale underlying this is that the arbitrage underlying the enforcement of the trilemma in the case of a peg and an open capital account operates on conventional interest rates. In Appendix E we report several robustness checks with alternative choices for the policy rates in the base-country and the local economy.

In terms of data, for conventional policy rates we in general consider central bank policy rates obtained from the IMF's International Financial Statistics and amended in a few cases by country-specific sources. For the shadow rates we consider those constructed by Wu and Xia (2016) for the US, the euro area and the UK, and the shadow rate constructed by Krippner (2013) for Japan. Figures 11 and 12 in Appendix D for each local economy plot the local policy rate together with the corresponding base-country policy rate.

\subsubsection{Exchange rate flexibility}

As in Shambaugh (2004), Obstfeld et al. (2005) and Klein and Shambaugh (2015), in our baseline specification we consider the de facto exchange rate regime classification of Shambaugh 
(2004) and Obstfeld et al. (2010). ${ }^{14}$ Under these classifications there are three exchange rate regimes, namely "peg", "soft-peg" and "float". In particular, a country-year observation is coded as "peg" by Shambaugh (2004) in a particular year if its bilateral exchange rate vis-àvis its base country stays within a $\pm 2 \%$ band over the course of that year, or if its exchange rate changes only in one month. A country-year observation is coded as "soft-peg" by Obstfeld et al. (2010) if it is not classified as "peg" and if the bilateral exchange rate vis-à-vis the base country stays within a $\pm 5 \%$ band in a given year, or if there is no month in which the exchange rate changes by more than $2 \%$ or less than $-2 \%$. All country-year observations that are neither classified as "peg" nor as "soft-peg" are classified as "float". The data for the exchange rate regime classification of Shambaugh (2004) are available until 2014. In order to estimate Taylor rules for the time period after 2014, we update the classification until December 2018.

The left-hand side panel in the top row of Figure 1 shows the distribution of country-month observations of the exchange rate regime classification of Shambaugh (2004) and Obstfeld et al. (2010) in our sample. About $63 \%$ of all country-month observations are classified as "peg" or "soft-peg". In order to translate the classification of Shambaugh (2004) into a binary classification required under our baseline specification, we consider "pegs" as well as "soft-pegs" as regimes with "limited exchange rate flexibility".

\subsubsection{Capital controls}

In our baseline specification we consider the capital controls indicator of Fernandez et al. (2016) as a measure of the degree of restrictions imposed on economies' capital account openness. This indicator builds on the data in Schindler (2009) and the IMF's Annual Report on Exchange Arrangements and Exchange Restrictions, and reflects capital control restrictions on both inflows and outflows for ten categories of instruments. The indicator has continuous, bounded support, with higher values reflecting tighter controls. The data for the capital controls indicator of Fernandez et al. (2016) are available until 2016. Unfortunately, updating the capital controls indicator is a major undertaking that is beyond the scope of this paper. Hence, in order to estimate Taylor rules for the time period until December 2018, in our baseline we assume the values of the capital controls indicator have not changed after 2015. Notice that although this is a relatively strong assumption, it is mitigated in our empirical framework. Specifically, below we transform the continuous capital controls assessment into a binary indicator based on some cut-off value. Hence, our assumption boils

\footnotetext{
${ }^{14}$ Other widely used exchange rate flexibility indicators are the de facto exchange rate regime indicator of Ilzetzki et al. (2017), the official IMF de facto classification described by Habermeier et al. (2009), as well as the de facto indicator of Levy-Yeyati and Sturzenegger (2016). However, Klein and Shambaugh (2015) advocate against the use of these exchange rate flexibility indicators for the purpose of testing the empirical validity of the trilemma. Specifically, the classification of Ilzetzki et al. (2017) codes countries as pegged if the black market exchange rate is stable, but that in some sense mixes two aspects of the trilemma, namely capital controls and exchange rate stability. For the purposes of examining the trilemma, a pure focus on the exchange rate as in the indicator of Shambaugh (2004) is more appropriate. Similarly, Levy-Yeyati and Sturzenegger (2016) use data on reserves volatility to assess whether an economy is intervening in order to maintain a peg. The index subsequently must add other pegs that do not intervene but that are clearly low volatility options.
} 
down to the values of the continuous capital controls index not crossing this cut-off value in 2017 and 2018. This is a much less strong assumption given the usually very gradual changes in the continuous capital controls index. The reason why we do not estimate the regression in Equation (4) only for the sample period for which the data on the capital controls indicator of Fernandez et al. (2016) is available is that we want to take into account the information in the data from the time period in which in particular the Federal Reserve left the effective lower bound, that is after 2015. Nevertheless, in robustness checks in Appendix E we run regressions on samples that end in 2015 .

The right-hand side panel in the top row of Figure 1 presents the distribution of countrymonth observations of the capital controls indicator of Fernandez et al. (2016) for the countries in our sample. In order to translate the continuous capital controls indicator into a binary variable, we choose a cut-off value that allocates observations into the regimes of "limited capital controls" and "extensive capital controls" such that the share of the sample that features "limited capital controls" equals the share that features "limited exchange rate flexibility". Specifically, we allocate a country-month observation to the regime with "capital controls" if the corresponding value of the capital controls indicator variable is below the $63 \%$ percentile of its distribution in our sample. Of course, the choice of the cut-off value for the "capital controls" regime is in principle arbitrary. However, notice that the cut-off value we choose has the appealing property that it can be interpreted as representing equal "treatment intensities" of exchange rate flexibility and capital controls as regards their effect on monetary policy autonomy under the trilemma.

\subsubsection{Policy configurations}

The panel in the bottom row of Figure 1 displays the distribution of country-month observations in our sample across economies' exchange rate flexibility and capital account openness configurations. Most observations in our sample are combinations of "limited exchange rate flexibility" and "limited capital controls". A smaller but similar share of observations is accounted for by combinations of "limited exchange rate flexibility" and "extensive capital controls" or vice versa, and the smallest share by combinations of "extensive exchange rate flexibility" and "extensive capital controls". Most importantly, Figure 1 documents that all policy configurations we consider account for non-trivial shares of our sample. Figures 9 and 10 in Appendix D provide detailed information on the policy configurations at the country level and over time.

\subsection{Baseline estimation results}

For each of the four regimes $j \in\{I, I I, I I I, I V\}$ Table 2 reports the results from the estimation of Equation (4). The coefficient estimates on the real-time GDP growth and inflation forecasts are almost all statistically significantly different from zero and have the expected sign. In contrast, essentially none of the coefficient estimates on the global variables is statistically significantly different from zero, consistent with the notion that the correlation 
between local and base-country policy rates induced by policymakers taking into account the effects of common shocks is largely captured by the real-time forecasts of local GDP growth and inflation.

The coefficient estimates for the sensitivity of the local to the base-country policy rate are always positive and statistically significant in all cases except for the regime with "extensive exchange rate flexibility" and "extensive capital controls". Moreover, the largest sensitivity to the base-country policy rate is estimated for economies with "limited exchange rate flexibility" and "limited capital controls"; smaller sensitivities for the regimes with "limited exchange rate flexibility" and "extensive capital controls" and vice versa; and the lowest - and least precisely estimated - sensitivity in the regime with "extensive exchange rate flexibility" and "extensive capital controls". The relative magnitudes of the estimates of $\alpha_{j}$ across regimes $j \in\{I, I I, I I I, I V\}$ are hence in line with the predictions from the trilemma in Equation (2), and thus the evidence for the 2000s supports the trilemma hypothesis: Both restricting capital account openness and exchange rate flexibility enhance monetary policy autonomy by reducing spillovers from base-country monetary policy. ${ }^{15}$

Figure 2 depicts scatter plots of the relationship between the left-hand side and the righthand side variables of interest in Equation (4), conditional on controlling for all other righthand side variables. The conditional scatterplots document that after controlling for the lagged local policy rate, real-time forecasts of local fundamentals and global variables the coefficient estimates for $\alpha_{j}$ reported in Table 2 are not driven by outliers. In Appendix $\mathrm{E}$ we document that these results are robust to varying the sample period, allowing for cross-country coefficient heterogeneity, exploring alternative specifications of the base-country policy rates and Taylor-rules, as well as imposing less structure on the data by estimating uncovered interest rate parity based regressions rather than Taylor rules.

\section{The financial channel of exchange rates and the trilemma}

\subsection{The mechanism and testable predictions}

Recent work has discussed the possibility that instead of insulating from base-country monetary policy, due to a financial channel flexible exchange rates might in fact amplify spillovers from base-country monetary policy to local financial conditions. For example, Bruno and Shin (2015) set up a model in which local banks fund their domestic lending by borrowing from

\footnotetext{
${ }^{15}$ The $p$-value for testing the null $H_{0}: \alpha_{I}>\alpha_{I I}\left(\alpha_{I I I}\right)$ is $0.22(0.09)$, and that of $H_{0}: \alpha_{I I}\left(\alpha_{I I I}\right)>\alpha_{I V}$ is $0.01(0.12)$. In order to formally test these hypothesis one needs to recover the regression results from the regime-specific regressions in Equation (4) in a single regression, which is achieved by interacting all righthand side variables with regime dummies, including the country fixed effects, and including regime dummies as regressors. Then, testing, say, $H_{0}: \alpha_{I}>\alpha_{I I}$ conditional upon having recovered the regime-specific regression results in a single regression is a one-sided test of a non-linear hypothesis. In particular, notice that rather than estimating the non-linear regression in Equation (4) we estimate

$$
i_{i t}^{p}=\chi_{i j}+\rho_{j} i_{i, t-1}^{p}+\widetilde{\boldsymbol{\phi}}_{j}^{\prime} \boldsymbol{x}_{i t}^{e}+\widetilde{\boldsymbol{\kappa}}_{j}^{\prime} \boldsymbol{z}_{t}+\widetilde{\alpha}_{j} i_{b_{i}, t}^{p}+\nu_{i t}
$$
}

and obtain $\widehat{\alpha}_{j}=\widehat{\widetilde{\alpha}}_{j} /\left(1-\widehat{\rho}_{j}\right)$. 
international banks, and in which local banks' borrowing capacity varies with the exchange rate: When the local currency appreciates, local borrowers' balance sheets that are subject to currency mismatches appear stronger, implying lower credit risk and hence increased borrowing capacity, and possibly resulting in a borrowing boom. In turn, when the local currency depreciates after local borrowers have taken advantage of previously cheap foreign-currency borrowing conditions, the boon turns into a bane in which lending is disrupted precipitously, possibly even putting at risk financial stability.

The existence of a financial channel of exchange rates that amplifies the spillovers from base-country monetary policy may also affect the empirical relevance of the policy trade-offs implied by the trilemma. Specifically, in the presence of foreign-currency exposures in order to attenuate the spillovers from base-country monetary policy through the financial channel of exchange rates, local policymakers may find it optimal to reduce exchange rate variation by limiting deviations from the base-country monetary policy stance even in the absence of an exchange rate peg. In other words, in specific circumstances due to the financial channel of exchange rates local monetary policy may purposely decide to mimic base-country monetary policy even in flexible exchange rate regimes. Recall that it is well-documented in theoretical work that it may be optimal for local monetary policy to limit exchange rate variability in the presence of foreign-currency denominated foreign debt (Cook, 2004; Choi and Cook, 2004; Elekdag and Tchakarov, 2007; Rappoport, 2009).

Of course another measure to reduce exchange rate variation available to policymakers in local economies is foreign exchange interventions. Our empirical analysis in this paper does not attempt to assess whether policymakers exploit foreign interventions. More importantly, our estimates cannot be driven by omitted variable bias stemming from not accounting for the possible recourse of local policymakers to foreign exchange interventions in our empirical framework. Specifically, suppose local policymakers also resorted to foreign exchange interventions to reduce exchange rate variation in the circumstances described above, in addition to mimicking the base-country policy rate. Since foreign exchange intervention does not impact the local policy rate, its true coefficient on the right-hand side of Equation (4) is zero. Hence, even if foreign exchange intervention is correlated with mimicking the base-country policy rate, not including it in the regression in Equation (4) does not produce omitted variable bias. Of course this is not to say that our finding that local economies may mimick the base-country policy rate in order to reduce exchange rate variation implies that they do not also use foreign exchange intervention to do so.

We explore the empirical validity of the hypothesis that the financial channel of exchange rates might have added a financial stability trade-off to the trilemma by testing for its predictions. Specifically, according to the mechanics of the financial channel of exchange rates a local economy with a flexible exchange rate will mimic base-country monetary policy in order to reduce exchange rate variation if its external balance sheet exhibits foreign-currency exposures. Hence, we test whether among the economies with "extensive exchange rate flexibility" in regimes III and IV the sensitivity of local to base-country policy rates is stronger for those economies which exhibit larger net short/smaller net long positions on their external balance sheets. To do so, we introduce an interaction term between the base-country policy rate and 
measures of the local economy's foreign-currency exposure in Equation (4). Specifically, we estimate the regression

$$
\begin{aligned}
i_{i t}^{p}=\chi_{i j}+\rho_{j} i_{i, t-1}+\boldsymbol{\theta}_{j}^{\prime} \boldsymbol{h}_{i t} & \\
& +\left(1-\rho_{j}\right)\left[\boldsymbol{\phi}_{j}^{\prime} \boldsymbol{x}_{i t}^{e}+\boldsymbol{\kappa}_{j}^{\prime} \boldsymbol{z}_{t}+\alpha_{j 1} \cdot i_{b_{i}, t}^{p}+\boldsymbol{\alpha}_{j 2}^{\prime} \cdot\left(i_{b_{i}, t}^{p} \times \boldsymbol{h}_{i t}\right)\right]+\nu_{i t},
\end{aligned}
$$

where $\boldsymbol{h}_{i t}$ represents a vector of measures of the local economy's foreign-currency exposure. ${ }^{16}$

\subsection{Foreign-currency exposure measurement and data}

We draw on the data on foreign-currency exposures from Lane and Shambaugh (2010) as well as the update provided by Benetrix et al. (2015). Lane and Shambaugh (2010) define the net foreign-currency exposure as the difference between an economy's foreign-currency denominated foreign assets and its foreign-currency denominated foreign liabilities, both scaled by domestic GDP. The net foreign-currency exposure is negative (positive) for an economy that is net short (long) in foreign currency on its external balance sheet. When an economy is net short in foreign currency, a depreciation of its currency implies an exchange rate valuation loss on its external balance sheet, as the local-currency value of its foreign assets declines and the local-currency value of its foreign liabilities rises. This setting corresponds to the scenario described above in which it becomes more difficult to service and to roll over foreign-currency liabilities for local agents in the face of a depreciation of the local currency.

Unfortunately, at the time of writing the data of Lane and Shambaugh (2010) as well as Benetrix et al. (2015) are available only until 2012. Hence, we estimate the sensitivity of local to base-country policy rates based on Equation (5) only for the time period between January 2002 and December 2012. A positive side effect is that we have much fewer instances of the effective zero lower bound being binding in the sample. For ease of interpretation of the corresponding coefficient estimates in the regression tables, we standardise the data on net foreign currency exposures in $\boldsymbol{h}_{i t}$. Finally, we consider economies' foreign-currency exposures excluding foreign exchange reserves. The top panel in Figure 3 presents the averages of economies' net foreign-currency exposures excluding foreign exchange reserves over the time period from 2002 to 2012; the values for Singapore and Switzerland are not shown due to their properties as an international financial center.

\subsection{Estimation results}

Column (1) in Table 3 reports the baseline regression results. Notice that the results reported in column (1) do not coincide with those reported in Table 2 for two reasons. First, the results in column (1) refer to the sample period from 2002 to 2012, while those in Table 2 to the sample period from 2002 to 2018. Second, the results in column (1) refer to a regression in which we include all country-month observations that featured "extensive exchange

\footnotetext{
${ }^{16}$ We also control for local economies' stock of foreign exchange reserves.
} 
rate flexibility", regardless of the degree of restrictions on economies' capital account openness; we report robustness checks below for regressions that are consider only country-month observations with "extensive exchange rate flexibility" and "extensive capital controls".

Column (2) in Table 3 reports the results from a regression in which we add interaction terms between the base-country policy rate and the local economy's net foreign-currency exposure. The results suggest that the sensitivity of the local to the base-country policy rate falls with the local economy's net foreign-currency exposure, that is it increases with its net short position and falls with its net long position. Specifically, a one-standard-deviation increase in the local economy's net foreign-currency exposure - that is the economy becoming more net long/less net short in foreign currency — essentially removes the positive sensitivity of local to base-country monetary policy. Hence, the effect of foreign-currency exposure on the sensitivity of local to base-country monetary policy is economically large. ${ }^{17}$

Column (3) reports results from regressions that allow us to distinguish between the effects of negative and positive net foreign currency exposures, respectively. The results suggest that reducing net short positions has a larger impact on the sensitivity of local to base-country policy rates than increasing net long positions. This result is consistent with the emphasis of negative foreign-currency exposures for the financial channel of exchange rates in Bruno and Shin (2015): When a local economy with a flexible exchange rate regime is net short in foreign currency, variations in the exchange rate that then elicit variations in the cost of servicing and rolling over foreign-currency liabilities are more likely to make firms' borrowing constraints bind.

Columns (4) and (5) present results from regressions that allow us to distinguish between the effects of net foreign currency exposures that stem from debt and non-debt instruments, respectively. ${ }^{18}$ The middle and bottom panel in Figure 3 present economies' debt and non-debt net foreign-currency exposures. The results suggest that the effects of net foreign currency exposures documented so far primarily stem from negative exposures through debt instruments, that is portfolio debt and bank loans. This finding suggests that only negative debt foreign currency exposures induce local monetary policy to mimic base-country monetary policy. This is again consistent with the emphasis on foreign-currency denominated foreign debt for the financial channel of exchange rate in Bruno and Shin (2015).

Next, columns (6) and (7) report results from regressions which allow us to distinguish between the debt net foreign currency exposures that stem from base-country and non-basecountry currencies, respectively. The results suggest that negative debt net foreign currency exposures due to both base-country and non-base-country currencies are associated with a higher sensitivity of local to base-country monetary policy. In principle, exchange rate

\footnotetext{
${ }^{17}$ Aizenman et al. (2017) in a different framework also find that the sensitivity of the local economy's financial conditions broadly defined to US shocks is larger in case of larger reliance on US dollar-denominated debt.

${ }^{18}$ In the data of Lane and Shambaugh (2010) as well as Benetrix et al. (2015) non-debt instruments are given by portfolio equity and FDI, and debt instruments by portfolio debt and other investment including bank loans. Lane and Shambaugh (2010) as well as Benetrix et al. (2015) assume that portfolio equity and FDI is always denominated in the currency of the issuer. Hence, a non-debt net foreign-currency exposure stems exclusively from holdings of foreign-currency denominated foreign portfolio equity and FDI and can only assume positive values.
} 
variation against any currency in which the local economy is net short on its external balance sheet may imply financial stability risks, and hence the finding of higher sensitivity in case of both non-base-country and base-country currency exposures is not surprising. And for many economies their bilateral exchange rates vis-à-vis the US dollar and the euro - the two base-country currencies we consider - correlates rather strongly; for example, the median correlation between local economies' exchange rates vis-à-vis the US dollar and the euro is 0.69 , and even at the $10 \%$ percentile it equals 0.33 . Nevertheless, debt net short positions stemming from base-country currency exposures have a somewhat stronger impact on the sensitivity of local to base-country policy rates; this finding emerges even more clearly in the robustness checks that we report below.

In the context of the impact of the financial channel of the exchange rate on the trilemma it is natural to explore asymmetries not only in the sign of economies' net foreign-currency exposure, but also in the direction of change of the base-country policy rate. Specifically, under the financial channel of exchange rates immediate risks to financial stability arise in particular in case of a depreciation of the local currency and negative foreign currency exposures. Hence, we run regressions analogous to Equation (5) in which we additionally introduce separate coefficients for the case in which the base-country policy rate is raised and lowered.

To start, column (2) in Table 4 reports results from a regression with separate coefficients for rises and declines in the base-country policy rate but without any net foreign-currency exposure variable. The results suggest that the sensitivity of the local to the base-country policy rate in economies with "extensive exchange rate flexibility" documented above in fact stems from cases in which base-country monetary policy is tightened.

Second, column (3) reports results from a regression in which we add interaction terms with local economies' net foreign-currency exposure, analogous to the regression specification in column (3) in Table 3. The results suggest that the sensitivity of the local to base-country policy rate when the latter is raised is attenuated the larger the local economy's net foreigncurrency exposure, that is the less net short/the more net long the local economy is on its external balance sheet.

Finally, column (4) reports results from a regression in which we again split the net foreigncurrency exposure in negative and positive values, analogous to column (4) in Table 3. The results are consistent with the prediction from the financial channel of exchange rates in the context of the trilemma that local policymakers may find it optimal to mimic base-country monetary policy in particular in order to reduce exchange rate depreciation when the local economy is net short in foreign currency.

These results are rather robust to considering only economies with "extensive exchange rate flexibility" and "limited capital controls" (Tables 5 and 6), including as control an interaction between base-country policy rate and the local economy's exchange rate pass-through to consumer prices as an alternative determinant of reluctance to allow for exchange rate variation (Tables 7 and 8) ${ }^{19}$, to running the regressions only until July 2007 (Tables 9 and

\footnotetext{
${ }^{19}$ We follow Campa and Goldberg (2005) as well as Hausmann et al. (2001) in estimating exchange rate
} 
10), to considering conventional instead of shadow policy rates (Tables 11 and 12), to considering only EMEs (Tables 13 and 14), as well as to dropping Singapore and Switzerland which exhibit very large net foreign currency exposures due to their properties as an international financial center.

\section{Conclusion}

We estimate Taylor rules for a broad panel of AEs and EMEs for the time period from 2002 to 2018 in order to evaluate the empirical validity of the trilemma. We find that the data are generally consistent with the predictions from the trilemma, in the sense that both exchange rate flexibility and restrictions on capital account openness reduce the impact of base-country on local policy rates. However, we also find that negative foreign-currency exposures on an economy's external balance sheet may limit the potential of flexible exchange rates to confer monetary policy autonomy, in particular when foreign-currency exposures is negative, when it stems from debt items and when base-country monetary policy is tightened. In this case, mimicking the base-country monetary policy tightening reduces exchange rate depreciation and thereby prevents negative valuation effects on the economy's external balance sheet from translating into risks to local financial stability. These findings are particularly relevant at the current juncture at which major AEs have started to normalise their monetary policy stance and EMEs are facing depreciation pressures.

pass-through to consumer prices. Appendix C.2 provides details. 


\section{References}

Aizenman, J., Chinn, M., Ito, H., 2013. The "Impossible Trinity" Hypothesis in an Era of Global Imbalances: Measurement and Testing. Review of International Economics 21 (3), 447-458. https://doi.org/10.1111/roie.12047

Aizenman, J., Chinn, M., Ito, H., 2016. Monetary Policy Spillovers and the Trilemma in the New Normal: Periphery Country Sensitivity to Core Country Conditions. Journal of International Money and Finance 68 (C),298-330.

https://doi.org/10.1016/j.jimonfin.2016.02.008

Aizenman, J., Chinn, M., Ito, H., 2017. Balance Sheet Effects on Monetary and Financial Spillovers: The East Asian Crisis Plus 20. Journal of International Money and Finance 74 (C), 258-282. https://doi.org/10.1016/j.jimonfin.2017.02.020

Avdjiev, S., Bruno, V., Koch, C., 2018. The Dollar Exchange Rate as a Global Risk Factor: Evidence from Investment. BIS Working Papers 695.

Bekaert, G., Mehl, A., 2017. On the Global Financial Market Integration "Swoosh" and the Trilemma. NBER Working Paper 23124. https://doi.org/10.3386/w23124

Benetrix, A., Lane, P., Shambaugh, J., 2015. International Currency Exposures, Valuation Effects and the Global Financial Crisis. Journal of International Economics 96 (S1), 98-209. https://doi.org/10.1016/j.jinteco.2014.11.002

Bernoth, K., Herwartz, H., 2019. Exchange Rates, Foreign Currency Exposure and Sovereign Risk. DIW Discussion Paper 1792.

Bluedorn, J., Bowdler, C., 2010. The Empirics of International Monetary Transmission: Identification and the Impossible Trinity. Journal of Money, Credit and Banking 42 (4), 679-713. https://doi.org/10.1111/j.1538-4616.2010.00303.x

Bräuning, F., Ivashina, V., 2018. US Monetary Policy and Emerging Market Credit Cycles. NBER Working Paper 25185.

Bruno, V., Shin, H. S., 2015. Cross-Border Banking and Global Liquidity. Review of Economic Studies 82 (2), 535-564. https://doi.org/10.1093/restud/rdu042

Caceres, C., Carriere-Swallow, Y., Gruss, B., 2016. Global Financial Conditions and Monetary Policy Autonomy. IMF Working Paper 16/108. https://doi.org/10.5089/9781484382066.001

Campa, J., Goldberg, L., 2005. Exchange Rate Pass-Through into Import Prices. The Review of Economics and Statistics 87 (4),679-690. https://doi.org/10.1162/003465305775098189

Cavallino, P., Sandri, D., 2018. The Expansionary Lower Bound: Contractionary Monetary Easing and the Trilemma. IMF Working Paper 18/236.

Cerutti, E., Claessens, S., Ratnovski, L., 2017. Global Liquidity and Cross-border Bank Flows. Economic Policy 32 (89), 81-125. https://doi.org/10.1093/epolic/eiw018

Choi, W. G., Cook, D., 2004. Liability Dollarization and the Bank Balance Sheet Channel. Journal of International Economics 64 (2), 247-275. https://doi.org/10.1016/j.jinteco.2003.08.009 
Clarida, R., Gali, J., Gertler, M., 1998. Monetary Policy Rules in Practice: Some International Evidence. European Economic Review 42 (6), 1033-1067. https://doi.org/10.1016/s0014-2921(98)00016-6

Clarida, R., Gali, J., Gertler, M., 2000. Monetary Policy Rules and Macroeconomic Stability: Evidence and Some Theory. The Quarterly Journal of Economics 115 (1), 147-180. https://doi.org/10.1162/003355300554692

Cook, D., 2004. Monetary Policy in Emerging Markets: Can Liability Dollarization Explain Contractionary Devaluations? Journal of Monetary Economics 51 (6), 1155-1181. https://doi.org/10.1016/j.jmoneco.2003.12.002

di Giovanni, J., Shambaugh, J., 2008. The Impact of Foreign Interest Rates on the Economy: The Role of the Exchange Rate Regime. Journal of International Economics 74 (2), 341361. https://doi.org/10.1016/j.jinteco.2007.09.002

Diamond, D., Hu, Y., Rajan, R., 2018. The Spillovers from Easy Liquidity and the Implications for Multilateralism. mimeo.

Dovern, J., Fritsche, U., Slacalek, J., 2012. Disagreement Among Forecasters in G7 Countries. The Review of Economics and Statistics 94 (4), 1081-1096. https://doi.org/10.1162/rest_a_00207

Durdu, C., Martin, A., Zer, I., 2018. The Role of US Monetary Policy in Global Banking Crises. mimeo.

Elekdag, S., Tchakarov, I., 2007. Balance Sheets, Exchange Rate Policy, and Welfare. Journal of Economic Dynamics and Control 31 (12), 3986-4015. https://doi.org/10.1016/j.jedc.2007.01.030

Fernandez, A., Klein, M., Rebucci, A., Schindler, M., Uribe, M., 2016. Capital Control Measures: A New Dataset. IMF Economic Review 64 (3), 548-574. https://doi.org/10.1057/imfer.2016.11

Frankel, J., Schmukler, S., Serven, L., 2004. Global Transmission of Interest Rates: Monetary Independence and Currency Regime. Journal of International Money and Finance 23 (5), 701-733. https://doi.org/10.1016/j.jimonfin.2004.03.006

Gourinchas, P.-O., Obstfeld, M., 2012. Stories of the Twentieth Century for the Twenty-First. American Economic Journal: Macroeconomics 4 (1), 226-265. https://doi.org/10.1257/mac.4.1.226

Habermeier, K., Kokenyne, A., Veyrune, R., Anderson, H., 2009. Revised System for the Classification of Exchange Rate Arrangements. IMF Working paper 09/211. https://doi.org/10.5089/9781451873580.001

Han, X., Wei, S.-J., 2018. International Transmissions of Monetary Shocks: Between a Trilemma and a Dilemma. Journal of International Economics 110, 205-219. https://doi.org/10.1016/j.jinteco.2017.11.005

Hausmann, R., Panizza, U., Stein, E., 2001. Why Do Countries Float the Way They Float? Journal of Development Economics 66 (2), 387-414. https://doi.org/10.1016/s0304$\underline{3878(01) 00168-7}$ 
Hofmann, B., Shim, I., Shin, H., 2017. Sovereign Yields and the Risk-taking Channel of Currency Appreciation. BIS Working Papers 538.

Hofmann, B., Takats, E., September 2015. International Monetary Spillovers. BIS Quarterly Review.

Ilzetzki, E., Reinhart, C., Rogoff, K., 2017. The Country Chronologies to Exchange Rate Arrangements into the 21st Century: Will the Anchor Currency Hold? NBER Working Paper 23135. https://doi.org/10.3386/w23135

Jorda, O., Schularick, M., Taylor, A., Ward, F., 2017. Global Financial Cycles and Risk Premiums. mimeo.

Judson, R., Owen, A., 1999. Estimating Dynamic Panel Data Models: A Guide for Macroeconomists. Economics Letters 65 (1), 9-15.

https://doi.org/10.1016/s0165-1765(99)00130-5

Kalemli-Ozcan, S., Liu, X., Shim, I., 2018. Exchange rate appreciations and corporate risk taking. BIS Working Papers (710).

Kearns, J., Patel, N., 2016. Does the Financial Channel of Exchange Rates Offset the Trade Channel? BIS Quarterly Review.

Kharroubi, E., Zampolli, F., 2016. Monetary Independence in a Financially Integrated World: What Do Measures of Interest Rate Co-movement Tell Us? BIS Papers 88.

Klein, M., Shambaugh, J., 2015. Rounding the Corners of the Policy Trilemma: Sources of Monetary Policy Autonomy. American Economic Journal: Macroeconomics 7 (4), 33-66. https://doi.org/10.1257/mac.20130237

Krippner,L., 2013. Measuring the Stance of Monetary Policy in Zero Lower Bound Environments. Economics Letters 118 (1), 135-138. https://doi.org/10.1016/j.econlet.2012.10.011

Lane, P., Shambaugh, J., 2010. Financial Exchange Rates and International Currency Exposures. American Economic Review 100 (1), 518-40.

https://doi.org/10.1257/aer.100.1.518

Levy-Yeyati, E.,Sturzenegger, F., 2016. Classifying Exchange Rate Regimes: 15Years Later. Harvard University John F. Kennedy School of Government Working Paper 16-028.

Miniane, J., Rogers, J., 2007. Capital Controls and the International Transmission of U.S. Money Shocks. Journal of Money, Credit and Banking 39 (5), 1003-1035. https://doi.org/10.1111/j.1538-4616.2007.00056.x

Niepmann, F., Schmidt-Eisenlohr, T., 2017. Foreign Currency Loans and Credit Risk: Evidence from U.S. Banks. CESifo Working Paper 6700.

Obstfeld, M., 2015. Trilemmas and Trade-offs: Living with Financial Globalisation. BIS Working Paper 480.

Obstfeld,M., Ostry, J., Qureshi, M., 2017.ATieThatBinds; Revisiting the Trilemmain Emerging Market Economies. IMF Working Paper 17/130. https://doi.org/10.5089/9781484302620.001 
Obstfeld, M., Shambaugh, J., Taylor, A., 2005. The Trilemma in History: Tradeoffs Among Exchange Rates, Monetary Policies, and Capital Mobility. The Review of Economics and Statistics 87 (3), 423-438. https://doi.org/10.1162/0034653054638300

Obstfeld, M., Shambaugh, J., Taylor,A., 2010. FinancialStability, the Trilemma, and International Reserves. American Economic Journal: Macroeconomics 2 (2), 57-94. https://doi.org/10.1257/mac.2.2.57

Passari, E., Rey, H., 2015. Financial Flows and the International Monetary System. Economic Journal 125 (584), 675-698. https://doi.org/10.1111/ecoj.12268

Pesaran, M., Shin, Y., 1999. An Autoregressive Distributed Lag Modelling Approach to Cointegration Analysis. In: Strom, S. (Ed.), Econometrics and Economic Theory in the 20th Century: The Ragnar Frisch Centennial Symposium. Cambridge: Cambridge University Press. https://doi.org/10.1017/CCOL521633230.011

Pesaran, M., Shin, Y., Smith, R., 2001. Bounds Testing Approaches to the Analysis of Level Relationships. Journal of Applied Econometrics 16 (3), 289-326. https://doi.org/10.1002/jae.616

Pesaran, M., Smith, R., 1995. Estimating Long-Run Relationships from Dynamic Heterogeneous Panels. Journal of Econometrics 68 (1), 79-113. https://doi.org/10.1016/03044076(94)01644-f

Rappoport, V., 2009. Persistence ofDollarization After Price Stabilization. Journal of Monetary Economics 56 (7), 979-989. https://doi.org/10.1016/j.jmoneco.2009.09.002

Rey, H., 2016. International Channels of Transmission of Monetary Policy and the Mundellian Trilemma. IMF Economic Review 64 (1), 6-35. https://doi.org/10.1057/imfer.2016.4

Ricci, L., Shi, W., 2016. Trilemma or Dilemma: Inspecting the Heterogeneous Response of Local Currency Interest Rates to Foreign Rates. IMF Working Paper 16/75. https://doi.org/10.5089/9781475522921.001

Rülke, J.-C., 2012. Are Central Bank Projections Rational? Applied Economics Letters 19, 1257-1263. https://doi.org/10.1080/13504851.2011.619482

Schindler, M., 2009. Measuring Financial Integration: A New Data Set. IMF Staff Papers 56 (1), 222-238. https://doi.org/10.1057/imfsp.2008.28

Shambaugh, J., 2004. The Effect of Fixed Exchange Rates on Monetary Policy. Quarterly Journal of Economics 119 (1), 301-352. https://doi.org/10.1162/003355304772839605

Wu, J., Xia, F., 2016. Measuring the Macroeconomic Impact of Monetary Policy at the Zero Lower Bound. Journal of Money, Credit and Banking 48 (2-3), 253-291. https://doi.org/10.1111/jmcb. 12300 


\section{A Tables}

Table 1: Economies included in the sample

\begin{tabular}{ll}
\hline Advanced & AUS, CAN, CHE, DNK, GBR, JPN, NOR, \\
& NZL, SWE \\
EM Europe & BGR, CZE, GEO, HUN, KAZ, POL, ROU, \\
& RUS, UKR \\
& BGD, CHN, HKG, IDN, IND, KOR, LKA, \\
EM Asia & MYS, PAK, PHL, SGP, THA, VNM \\
EM Latin America & BOL, BRA, CHL, COL, CRI, DOM, MEX, \\
EM Middle East and Africa & EGY, ISR, NGA, SAU, TUR, ZAF \\
\hline
\end{tabular}

Table 2: Baseline estimation results

\begin{tabular}{|c|c|c|c|c|}
\hline & $\begin{array}{l}\text { (1) } \\
\text { Lim. FX flex. } \\
\text { \& Lim. CCs }\end{array}$ & $\begin{array}{l}\text { Lim. } \stackrel{(2)}{\text { FX flex. }} \\
\text { \& Ext. CCs }\end{array}$ & $\begin{array}{l}\text { Ext. } \stackrel{(3)}{\text { FX flex. }} \text {. } \\
\text { \& Lim. CCs }\end{array}$ & \begin{tabular}{l}
\multicolumn{1}{c}{$(4)$} \\
Ext. $\stackrel{\text { FX flex. }}{\text { \& Ext. CCs }}$
\end{tabular} \\
\hline GDP growth forecast & $\begin{array}{c}0.79^{* * *} \\
(0.00)\end{array}$ & $\begin{array}{l}0.29 \\
(0.23)\end{array}$ & $\begin{array}{c}1.80^{* *} \\
(0.03)\end{array}$ & $\begin{array}{c}0.74 \\
(0.19)\end{array}$ \\
\hline Inflation forecast & $\begin{array}{c}0.51^{* *} \\
(0.05)\end{array}$ & $\begin{array}{l}0.43^{*} \\
(0.08)\end{array}$ & $\begin{array}{c}1.50^{* *} \\
(0.05)\end{array}$ & $\begin{array}{c}1.59^{* * *} \\
(0.00)\end{array}$ \\
\hline VIX & $\begin{array}{l}-0.07 \\
(0.11)\end{array}$ & $\begin{array}{l}-0.05 \\
(0.28)\end{array}$ & $\begin{array}{l}0.04 \\
(0.48)\end{array}$ & $\begin{array}{l}-0.03 \\
(0.45)\end{array}$ \\
\hline Commodity prices & $\begin{array}{l}9.64 \\
(0.17)\end{array}$ & $\begin{array}{l}2.53 \\
(0.78)\end{array}$ & $\begin{array}{l}24.06 \\
(0.12)\end{array}$ & $\begin{array}{l}-11.14 \\
(0.28)\end{array}$ \\
\hline Base-country policy rate & $\begin{array}{c}0.76^{* * *} \\
(0.00)\end{array}$ & $\begin{array}{c}0.61^{* * *} \\
(0.00)\end{array}$ & $\begin{array}{l}0.45^{* *} \\
(0.02)\end{array}$ & $\begin{array}{l}0.20 \\
(0.15)\end{array}$ \\
\hline R-squared (within) & 0.03 & 0.05 & 0.05 & 0.05 \\
\hline Observations & 2850 & 1671 & 1400 & 1070 \\
\hline Countries & 27 & 17 & 25 & 16 \\
\hline
\end{tabular}


Table 3: The financial channel of exchange rates and the trilemma

\begin{tabular}{|c|c|c|c|c|c|c|c|}
\hline & (1) & (2) & (3) & (4) & $(5)$ & (6) & (7) \\
\hline Base-country policy rate & $0.52^{*}$ & $0.40^{* *}$ & $0.39^{* * *}$ & $0.41^{* * *}$ & $0.37^{* * *}$ & $0.39^{* * *}$ & $0.39^{* * *}$ \\
\hline$\times$ NFX (excl. reserves) & & $-0.54^{* *}$ & & & & & \\
\hline$\times \mathrm{NFX}($ excl. reserves $) \times \mathrm{I}(\mathrm{NFX} \geq 0)$ & & & $-0.48^{* *}$ & & & & \\
\hline$\times$ NFX $($ excl. reserves $) \times \mathrm{I}(\mathrm{NFX}<0)$ & & & $-0.68^{* *}$ & & & & \\
\hline$\times$ Non-debt NFX & & & & $\frac{-0.27}{(0.17)}$ & $\begin{array}{c}-0.35^{* *} \\
(0.04)\end{array}$ & $\begin{array}{l}-0.23 \\
(0.19)\end{array}$ & $\begin{array}{c}-0.42^{* *} \\
(0.02)\end{array}$ \\
\hline$\times$ Debt NFX & & & & $-0.37^{* * *}$ & & & \\
\hline$\times$ Debt NFX $\times \mathrm{I}(\mathrm{NFX} \geq 0)$ & & & & & -0.06 & & \\
\hline$\times$ Debt NFX $\times \mathrm{I}(\mathrm{NFX}<0)$ & & & & & $\begin{array}{c}-0.53^{* * *} \\
(0.00)\end{array}$ & & \\
\hline$\times$ Base-country-currency debt NFX & & & & & & $\frac{-0.01}{(0.92)}$ & \\
\hline$\times$ Base-country-currency debt $\mathrm{NFX} \times \mathrm{I}(\mathrm{NFX} \geq 0)$ & & & & & & & 0.48 \\
\hline$\times$ Base-country-currency debt NFX $\times \mathrm{I}(\mathrm{NFX}<0)$ & & & & & & & $-0.49^{* *}$ \\
\hline$\times$ Non-base-country-currency debt NFX & & & & & & $\begin{array}{c}-0.34 * * * \\
(0.01)\end{array}$ & \\
\hline$\times$ Non-base-country-currency debt $\mathrm{NFX} \times \mathrm{I}(\mathrm{NFX} \geq 0)$ & & & & & & & -0.34 \\
\hline$\times$ Non-base-country-currency debt $\mathrm{NFX} \times \mathrm{I}(\mathrm{NFX}<0)$ & & & & & & & $\begin{array}{c}-0.40^{* * * *} \\
(0.00)\end{array}$ \\
\hline R-squared (within) & 0.05 & 0.08 & 0.09 & 0.08 & 0.09 & 0.08 & 0.09 \\
\hline Observations & 1737 & 1623 & 1623 & 1623 & 1623 & 1623 & 1623 \\
\hline Countries & 38 & 36 & 36 & 36 & 36 & 36 & 36 \\
\hline
\end{tabular}

$p$-values in parentheses

Driscoll-Kraay robust standard errors. Coefficient estimates of Taylor-rule fundamentals not reported.

${ }^{*} p<0.1,{ }^{* *} p<0.05,{ }^{* * *} p<0.01$

Table 4: Accounting for asymmetries in base-country policy rate changes under the financial channel of exchange rates and the trilemma

\begin{tabular}{|c|c|c|c|c|}
\hline & (1) & $(2)$ & $(3)$ & $(4)$ \\
\hline Base-country policy rate & $\begin{array}{c}0.52^{*} \\
(0.06)\end{array}$ & & & \\
\hline Base-country policy rate $\times \mathrm{I}\left(\Delta i_{b_{i}, t}^{p} \geq 0\right)$ & & $\begin{array}{c}0.59^{* *} \\
(0.04)\end{array}$ & $\begin{array}{c}0.41^{* *} \\
(0.02)\end{array}$ & $\begin{array}{l}-0.03 \\
(0.93)\end{array}$ \\
\hline Base-country policy rate $\times \mathrm{I}\left(\Delta i_{b_{i}, t}^{p} \geq 0\right) \times$ Net FX exposure & & & $\begin{array}{l}-0.55^{* *} \\
(0.04)\end{array}$ & \\
\hline Base-country policy rate $\times \mathrm{I}\left(\Delta i_{b_{i}, t}^{p} \geq 0\right) \times$ Net FX exposure $\times \mathrm{I}(\mathrm{NFX} \geq 0)$ & & & & $\begin{array}{l}0.22 \\
(0.54)\end{array}$ \\
\hline Base-country policy rate $\times \mathrm{I}\left(\Delta i_{b_{i}, t}^{p} \geq 0\right) \times$ Net $\mathrm{FX}$ exposure $\times \mathrm{I}(\mathrm{NFX}<0)$ & & & & $-1.73^{*}$ \\
\hline Base-country policy rate $\times \mathrm{I}\left(\Delta i_{b_{i}, t}^{p}<0\right)$ & & $\begin{array}{l}-2.32 \\
(0.20)\end{array}$ & $\begin{array}{c}-0.83 \\
(0.36)\end{array}$ & $\begin{array}{l}-0.24 \\
(0.86)\end{array}$ \\
\hline Base-country policy rate $\times \mathrm{I}\left(\Delta i_{b_{i}, t}^{p}<0\right) \times$ Net FX exposure & & & $\begin{array}{l}1.26 \\
(0.19)\end{array}$ & \\
\hline Base-country policy rate $\times \mathrm{I}\left(\Delta i_{b_{i}, t}^{p}<0\right) \times$ Net $\mathrm{FX}$ exposure $\times \mathrm{I}(\mathrm{NFX} \geq 0)$ & & & & $\begin{array}{l}1.07 \\
(0.23)\end{array}$ \\
\hline Base-country policy rate $\times \mathrm{I}\left(\Delta i_{b_{i}, t}^{p}<0\right) \times$ Net FX exposure $\times \mathrm{I}(\mathrm{NFX}<0)$ & & & & $\begin{array}{l}3.03 \\
(0.25)\end{array}$ \\
\hline R-squared (within) & 0.05 & 0.05 & 0.09 & 0.09 \\
\hline Observations & 1737 & 1737 & 1623 & 1623 \\
\hline Countries & 38 & 38 & 36 & 36 \\
\hline
\end{tabular}

$p$-values in parentheses

Driscoll-Kraay robust standard errors. Coefficient estimates of Taylor-rule fundamentals not reported.

${ }^{*} p<0.1,{ }^{* *} p<0.05,{ }^{* * *} p<0.01$ 
Table 5: The financial channel of exchange rates and the trilemma, estimated only for regime III

\begin{tabular}{|c|c|c|c|c|c|c|c|}
\hline & (1) & $(2)$ & $(3)$ & $(4)$ & $(5)$ & $(6)$ & $(7)$ \\
\hline Base-country policy rate & $\begin{array}{c}0.54^{* *} \\
(0.03)\end{array}$ & $\begin{array}{c}0.35^{*} \\
(0.09)\end{array}$ & $\begin{array}{c}0.32^{*} \\
(0.06)\end{array}$ & $\begin{array}{l}0.32 \\
(0.16)\end{array}$ & $\begin{array}{l}0.11 \\
0.60)\end{array}$ & $\begin{array}{l}0.29 \\
(0.30)\end{array}$ & $\begin{array}{l}0.26 \\
(0.34)\end{array}$ \\
\hline$\times$ NFX (excl. reserves) & & $\begin{array}{l}-1.13^{* * *} \\
(0.01)\end{array}$ & & & & & \\
\hline$\times \operatorname{NFX}($ excl. reserves $) \times \mathrm{I}(\mathrm{NFX} \geq 0)$ & & & $\begin{array}{l}-0.85^{* *} \\
(0.03)\end{array}$ & & & & \\
\hline$\times \operatorname{NFX}($ excl. reserves $) \times \mathrm{I}(\mathrm{NFX}<0)$ & & & $\begin{array}{c}-0.98^{*} \\
(0.06)\end{array}$ & & & & \\
\hline$\times$ Non-debt NFX & & & & $\begin{array}{c}-0.87 \\
(0.25)\end{array}$ & $\begin{array}{l}-0.56 \\
(0.49)\end{array}$ & $\begin{array}{l}-0.76 \\
(0.37)\end{array}$ & $\begin{array}{c}-1.26^{* *} \\
(0.05)\end{array}$ \\
\hline$\times$ Debt NFX & & & & $\begin{array}{c}-0.50^{*} \\
(0.08)\end{array}$ & & & \\
\hline$\times$ Debt $\mathrm{NFX} \times \mathrm{I}(\mathrm{NFX} \geq 0)$ & & & & & $\begin{array}{l}0.18 \\
(0.71)\end{array}$ & & \\
\hline$\times$ Debt NFX $\times$ I $(\mathrm{NFX}<0)$ & & & & & $\begin{array}{c}-0.58^{*} \\
(0.09)\end{array}$ & & \\
\hline$\times$ Base-country-currency debt NFX & & & & & & $\begin{array}{c}-0.11 \\
(0.87)\end{array}$ & \\
\hline$\times$ Base-country-currency debt NFX $\times \mathrm{I}(\mathrm{NFX} \geq 0)$ & & & & & & & $\begin{array}{l}-2.28 \\
(0.12)\end{array}$ \\
\hline$\times$ Base-country-currency debt $\mathrm{NFX} \times \mathrm{I}(\mathrm{NFX}<0)$ & & & & & & & $-1.21^{* *}$ \\
\hline$\times$ Non-base-country-currency debt NFX & & & & & & $\begin{array}{l}-0.35 \\
(0.14)\end{array}$ & \\
\hline$\times$ Non-base-country-currency debt $\mathrm{NFX} \times \mathrm{I}(\mathrm{NFX} \geq 0)$ & & & & & & & $\begin{array}{l}0.56 \\
(0.35)\end{array}$ \\
\hline$\times$ Non-base-country-currency debt $\mathrm{NFX} \times \mathrm{I}(\mathrm{NFX}<0)$ & & & & & & & $\begin{array}{c}-0.68^{* *} \\
(0.04)\end{array}$ \\
\hline R-squared (within) & 0.11 & 0.13 & 0.16 & 0.13 & 0.14 & 0.14 & 0.16 \\
\hline Observations & 783 & 771 & 771 & 771 & 771 & 771 & 771 \\
\hline Countries & 22 & 21 & 21 & 21 & 21 & 21 & 21 \\
\hline
\end{tabular}

$p$-values in parentheses

Driscoll-Kraay robust standard errors. Coefficient estimates of Taylor-rule fundamentals not reported.

${ }^{*} p<0.1,{ }^{* *} p<0.05,{ }^{* * *} p<0.01$

Table 6: Accounting for asymmetries in base-country policy rate changes under the financial channel of exchange rates and the trilemma, estimated only for regime III

\begin{tabular}{|c|c|c|c|c|}
\hline & $(1)$ & $(2)$ & $(3)$ & $(4)$ \\
\hline Base-country policy rate & $\begin{array}{c}0.54^{* *} \\
(0.03)\end{array}$ & & & \\
\hline Base-country policy rate $\times \mathrm{I}\left(\Delta i_{b_{i}, t}^{p} \geq 0\right)$ & & $\begin{array}{c}0.56^{* *} \\
(0.02)\end{array}$ & $\begin{array}{l}0.34 \\
(0.12)\end{array}$ & $\begin{array}{l}0.25 \\
(0.40)\end{array}$ \\
\hline Base-country policy rate $\times \mathrm{I}\left(\Delta i_{b_{i}, t}^{p} \geq 0\right) \times$ Net FX exposure & & & $-1.15^{* * *}$ & \\
\hline Base-country policy rate $\times \mathrm{I}\left(\Delta i_{b_{i}, t}^{p} \geq 0\right) \times$ Net FX exposure $\times \mathrm{I}(\mathrm{NFX} \geq 0)$ & & & & $\begin{array}{c}-0.99 \\
(0.14)\end{array}$ \\
\hline Base-country policy rate $\times \mathrm{I}\left(\Delta i_{b_{i}, t}^{p} \geq 0\right) \times$ Net FX exposure $\times \mathrm{I}(\mathrm{NFX}<0)$ & & & & $\begin{array}{l}-1.30 \\
(0.11)\end{array}$ \\
\hline Base-country policy rate $\times \mathrm{I}\left(\Delta i_{b_{i}, t}^{p}<0\right)$ & & $\begin{array}{c}-0.07 \\
(0.96)\end{array}$ & $\begin{array}{l}0.35 \\
(0.77)\end{array}$ & $\begin{array}{l}1.72 \\
(0.30)\end{array}$ \\
\hline Base-country policy rate $\times \mathrm{I}\left(\Delta i_{b_{i}, t}^{p}<0\right) \times$ Net $\mathrm{FX}$ exposure & & & $\begin{array}{l}0.78 \\
(0.58)\end{array}$ & \\
\hline Base-country policy rate $\times \mathrm{I}\left(\Delta i_{b_{i}, t}^{p}<0\right) \times$ Net FX exposure $\times \mathrm{I}(\mathrm{NFX} \geq 0)$ & & & & $\begin{array}{c}-0.82 \\
(0.32)\end{array}$ \\
\hline Base-country policy rate $\times \mathrm{I}\left(\Delta i_{b_{i}, t}^{p}<0\right) \times$ Net FX exposure $\times \mathrm{I}(\mathrm{NFX}<0)$ & & & & $\begin{array}{l}6.47 \\
(0.31)\end{array}$ \\
\hline R-squared (within) & 0.11 & 0.11 & 0.14 & 0.14 \\
\hline Observations & 783 & 783 & 771 & 771 \\
\hline Countries & 22 & 22 & 21 & 21 \\
\hline
\end{tabular}

$p$-values in parentheses

Driscoll-Kraay robust standard errors. Coefficient estimates of Taylor-rule fundamentals not reported.

${ }^{*} p<0.1,{ }^{* *} p<0.05,{ }^{* * *} p<0.01$ 
Table 7: The financial channel of exchange rates and the trilemma, adding ERPT interacted with base-country policy rate as control

\begin{tabular}{|c|c|c|c|c|c|c|c|}
\hline & (1) & $(2)$ & $(3)$ & $(4)$ & $(5)$ & $(6)$ & $(7)$ \\
\hline Base-country policy rate & $\begin{array}{l}0.52^{*} \\
(0.06)\end{array}$ & $\begin{array}{c}0.45^{* * *} \\
(0.01)\end{array}$ & $\begin{array}{c}0.44^{* * *} \\
(0.00)\end{array}$ & $\begin{array}{c}0.45^{* * *} \\
(0.00)\end{array}$ & $\begin{array}{c}0.33^{* *} \\
(0.05)\end{array}$ & $\begin{array}{c}0.38^{* *} \\
(0.03)\end{array}$ & $\begin{array}{c}0.42^{* * *} \\
(0.01)\end{array}$ \\
\hline$\times$ NFX (excl. reserves) & & $\begin{array}{c}-0.54^{* *} \\
(0.04)\end{array}$ & & & & & \\
\hline$\times \operatorname{NFX}($ excl. reserves $) \times \mathrm{I}(\mathrm{NFX} \geq 0)$ & & & $\begin{array}{l}-0.51^{* *} \\
(0.03)\end{array}$ & & & & \\
\hline$\times \operatorname{NFX}($ excl. reserves $) \times \mathrm{I}(\mathrm{NFX}<0)$ & & & $\begin{array}{c}-0.71^{*} \\
(0.06)\end{array}$ & & & & \\
\hline$\times$ Debt NFX & & & & $\begin{array}{l}-0.36^{* * *} \\
(0.01)\end{array}$ & & & \\
\hline$\times$ Debt $\mathrm{NFX} \times \mathrm{I}(\mathrm{NFX} \geq 0)$ & & & & & $\begin{array}{c}-0.00 \\
(0.98)\end{array}$ & & \\
\hline$\times$ Debt $\mathrm{NFX} \times \mathrm{I}(\mathrm{NFX}<0)$ & & & & & $\begin{array}{l}-0.53^{* * *} \\
(0.01)\end{array}$ & & \\
\hline$\times$ Base-country-currency debt NFX & & & & & & $\begin{array}{l}0.06 \\
(0.68)\end{array}$ & \\
\hline$\times$ Non-base-country-currency debt NFX & & & & & & $\begin{array}{c}-0.35^{* *} \\
(0.02)\end{array}$ & \\
\hline$\times$ Non-base-country-currency debt $\mathrm{NFX} \times \mathrm{I}(\mathrm{NFX} \geq 0)$ & & & & & & & $\begin{array}{c}-0.34 \\
(0.39)\end{array}$ \\
\hline$\times$ Non-base-country-currency debt NFX $\times$ I $(\mathrm{NFX}<0)$ & & & & & & & $\begin{aligned}-0.40^{* * *} & (0.00)\end{aligned}$ \\
\hline R-squared (within) & 0.05 & 0.08 & 0.09 & 0.08 & 0.08 & 0.08 & 0.09 \\
\hline Observations & 1737 & 1533 & 1533 & 1533 & 1533 & 1533 & 1533 \\
\hline Countries & 38 & 35 & 35 & 35 & 35 & 35 & 35 \\
\hline
\end{tabular}

$p$-values in parentheses

Driscoll-Kraay robust standard errors. Coefficient estimates of Taylor-rule fundamentals not reported.

${ }^{*} p<0.1,{ }^{* *} p<0.05,{ }^{* * *} p<0.01$

Table 8: Accounting for asymmetries in base-country policy rate changes under the financial channel of exchange rates and the trilemma, adding ERPT interacted with base-country policy rate as control

\begin{tabular}{|c|c|c|c|c|}
\hline & (1) & $(2)$ & (3) & (4) \\
\hline Base-country policy rate & $\begin{array}{c}0.52^{*} \\
(0.06)\end{array}$ & & & \\
\hline Base-country policy rate $\times \mathrm{I}\left(\Delta i_{b_{i}, t}^{p} \geq 0\right)$ & & $\begin{array}{c}0.63^{* *} \\
(0.02)\end{array}$ & $\begin{array}{c}0.45^{* * *} \\
(0.01)\end{array}$ & $\begin{array}{l}0.02 \\
(0.95)\end{array}$ \\
\hline Base-country policy rate $\times \mathrm{I}\left(\Delta i_{b_{i}, t}^{p} \geq 0\right) \times$ Net FX exposure & & & $\begin{array}{c}-0.54^{*} \\
(0.06)\end{array}$ & \\
\hline Base-country policy rate $\times \mathrm{I}\left(\Delta i_{b_{i}, t}^{p} \geq 0\right) \times$ Net $\mathrm{FX}$ exposure $\times \mathrm{I}(\mathrm{NFX} \geq 0)$ & & & & $\begin{array}{l}0.21 \\
(0.58)\end{array}$ \\
\hline Base-country policy rate $\times \mathrm{I}\left(\Delta i_{b_{i}, t}^{p} \geq 0\right) \times$ Net FX exposure $\times \mathrm{I}(\mathrm{NFX}<0)$ & & & & $\begin{array}{c}-1.85^{* *} \\
(0.05)\end{array}$ \\
\hline Base-country policy rate $\times \mathrm{I}\left(\Delta i_{b_{i}, t}^{p}<0\right)$ & & $\begin{array}{l}-2.45 \\
(0.27)\end{array}$ & $\begin{array}{c}-0.99 \\
(0.38)\end{array}$ & $\begin{array}{l}0.01 \\
(0.99)\end{array}$ \\
\hline Base-country policy rate $\times \mathrm{I}\left(\Delta i_{b_{i}, t}^{p}<0\right) \times$ Net FX exposure & & & $\begin{array}{l}1.50 \\
(0.20)\end{array}$ & \\
\hline Base-country policy rate $\times \mathrm{I}\left(\Delta i_{b_{i}, t}^{p}<0\right) \times$ Net FX exposure $\times \mathrm{I}(\mathrm{NFX} \geq 0)$ & & & & $\begin{array}{l}0.96 \\
(0.27)\end{array}$ \\
\hline Base-country policy rate $\times \mathrm{I}\left(\Delta i_{b_{i}, t}^{p}<0\right) \times$ Net FX exposure $\times \mathrm{I}(\mathrm{NFX}<0)$ & & & & $\begin{array}{l}4.55^{*} \\
(0.09)\end{array}$ \\
\hline R-squared (within) & 0.05 & 0.05 & 0.08 & 0.09 \\
\hline Observations & 1737 & 1647 & 1533 & 1533 \\
\hline Countries & 38 & 37 & 35 & 35 \\
\hline
\end{tabular}


Table 9: The financial channel of exchange rates and the trilemma, estimated only until 2007

\begin{tabular}{|c|c|c|c|c|c|c|c|}
\hline & (1) & (2) & (3) & (4) & $(5)$ & (6) & (7) \\
\hline$\overline{\text { Base-country policy rate }}$ & $\begin{array}{l}0.23 \\
(0.28)\end{array}$ & $\begin{array}{c}0.46^{* * *} \\
(0.00)\end{array}$ & $\begin{array}{c}0.50^{* * * *} \\
(0.00)\end{array}$ & $\begin{array}{l}0.45^{* * *} \\
(0.00)\end{array}$ & $\begin{array}{l}0.46^{* * *} \\
(0.00)\end{array}$ & $\begin{array}{l}0.46^{* * *} \\
(0.00)\end{array}$ & $\begin{array}{c}0.42^{* * *} \\
(0.00)\end{array}$ \\
\hline$\times$ NFX (excl. reserves) & & $\begin{array}{l}0.05 \\
(0.55)\end{array}$ & & & & & \\
\hline$\times \mathrm{NFX}($ excl. reserves $) \times \mathrm{I}(\mathrm{NFX} \geq 0)$ & & & $\begin{array}{l}0.03 \\
(0.67)\end{array}$ & & & & \\
\hline$\times$ NFX $($ excl. reserves $) \times \mathrm{I}(\mathrm{NFX}<0)$ & & & $\begin{array}{c}-0.31 \\
(0.11)\end{array}$ & & & & \\
\hline$\times$ Non-debt NFX & & & & $\begin{array}{c}0.11 \\
(0.37)\end{array}$ & $\begin{array}{l}0.11 \\
(0.38)\end{array}$ & $\begin{array}{l}0.11 \\
(0.36)\end{array}$ & $\frac{-0.01}{(0.90)}$ \\
\hline$\times$ Debt NFX & & & & $\begin{array}{l}-0.09 \\
(0.29)\end{array}$ & & & \\
\hline$\times$ Debt NFX $\times \mathrm{I}(\mathrm{NFX} \geq 0)$ & & & & & -0.04 & & \\
\hline$\times$ Debt $\mathrm{NFX} \times \mathrm{I}(\mathrm{NFX}<0)$ & & & & & $\begin{array}{l}-0.11 \\
(0.39)\end{array}$ & & \\
\hline$\times$ Base-country-currency debt NFX & & & & & & $\begin{array}{l}-0.06 \\
(0.42)\end{array}$ & \\
\hline$\times$ Base-country-currency debt NFX $\times \mathrm{I}(\mathrm{NFX} \geq 0)$ & & & & & & & $\begin{array}{c}-0.07 \\
(0.55)\end{array}$ \\
\hline$\times$ Base-country-currency debt NFX $\times \mathrm{I}(\mathrm{NFX}<0)$ & & & & & & & $-0.28^{* * *}$ \\
\hline$\times$ Non-base-country-currency debt NFX & & & & & & $\begin{array}{c}-0.04 \\
(0.68)\end{array}$ & \\
\hline$\times$ Non-base-country-currency debt NFX $\times \mathrm{I}(\mathrm{NFX} \geq 0)$ & & & & & & & $\begin{array}{l}0.06 \\
(0.69)\end{array}$ \\
\hline$\times$ Non-base-country-currency debt NFX $\times \mathrm{I}(\mathrm{NFX}<0)$ & & & & & & & $\begin{array}{c}-0.18^{*} \\
(0.09)\end{array}$ \\
\hline R-squared (within) & 0.07 & 0.10 & 0.10 & 0.10 & 0.10 & 0.10 & 0.11 \\
\hline Observations & 997 & 931 & 931 & 931 & 931 & 931 & 931 \\
\hline Countries & 29 & 28 & 28 & 28 & 28 & 28 & 28 \\
\hline
\end{tabular}

p-values in parentheses

Driscoll-Kraay robust standard errors. Coefficient estimates of Taylor-rule fundamentals not reported.

${ }^{*} p<0.1,{ }^{* *} p<0.05,{ }^{* * *} p<0.01$

Table 10: Accounting for asymmetries in base-country policy rate changes under the financial channel of exchange rates and the trilemma, estimated only until 2007

\begin{tabular}{|c|c|c|c|c|}
\hline & (1) & (2) & (3) & (4) \\
\hline Base-country policy rate & $\begin{array}{l}0.23 \\
(0.28)\end{array}$ & & & \\
\hline Base-country policy rate $\times \mathrm{I}\left(\Delta i_{b_{i}, t}^{p} \geq 0\right)$ & & $\begin{array}{l}0.19 \\
(0.42)\end{array}$ & $\begin{array}{c}0.45^{* * *} \\
(0.00)\end{array}$ & $\begin{array}{r}0.19 \\
(0.45)\end{array}$ \\
\hline Base-country policy rate $\times \mathrm{I}\left(\Delta i_{b_{i}, t}^{p} \geq 0\right) \times$ Net FX exposure & & & $\begin{array}{l}0.07 \\
(0.49)\end{array}$ & \\
\hline Base-country policy rate $\times \mathrm{I}\left(\Delta i_{b_{i}, t}^{p} \geq 0\right) \times$ Net FX exposure $\times \mathrm{I}(\mathrm{NFX} \geq 0)$ & & & & $\begin{array}{l}0.24 \\
(0.14)\end{array}$ \\
\hline Base-country policy rate $\times \mathrm{I}\left(\Delta i_{b_{i}, t}^{p} \geq 0\right) \times$ Net FX exposure $\times \mathrm{I}(\mathrm{NFX}<0)$ & & & & -0.62 \\
\hline Base-country policy rate $\times \mathrm{I}\left(\Delta i_{b_{i}, t}^{p}<0\right)$ & & $\begin{array}{l}-2.58^{*} \\
(0.06)\end{array}$ & $\begin{array}{c}-1.80^{*} \\
(0.08)\end{array}$ & $\begin{array}{l}-1.83 \\
(0.14)\end{array}$ \\
\hline Base-country policy rate $\times \mathrm{I}\left(\Delta i_{b_{i}, t}^{p}<0\right) \times$ Net FX exposure & & & $\begin{array}{l}0.18 \\
(0.73)\end{array}$ & \\
\hline Base-country policy rate $\times \mathrm{I}\left(\Delta i_{b_{i}, t}^{p}<0\right) \times$ Net FX exposure $\times \mathrm{I}(\mathrm{NFX} \geq 0)$ & & & & $\begin{array}{l}0.28 \\
(0.68)\end{array}$ \\
\hline Base-country policy rate $\times \mathrm{I}\left(\Delta i_{b_{i}, t}^{p}<0\right) \times$ Net FX exposure $\times \mathrm{I}(\mathrm{NFX}<0)$ & & & & $\begin{array}{c}-0.41 \\
(0.67)\end{array}$ \\
\hline R-squared (within) & 0.07 & 0.10 & 0.12 & 0.13 \\
\hline Observations & 997 & 997 & 931 & 931 \\
\hline Countries & 29 & 29 & 28 & 28 \\
\hline
\end{tabular}

$p$-values in parentheses

Driscoll-Kraay robust standard errors. Coefficient estimates of Taylor-rule fundamentals not reported.

${ }^{*} p<0.1,{ }^{* *} p<0.05,{ }^{* * *} p<0.01$ 
Table 11: The financial channel of exchange rates and the trilemma, using conventional policy rates

\begin{tabular}{|c|c|c|c|c|c|c|c|}
\hline & (1) & $(2)$ & (3) & (4) & (5) & (6) & (7) \\
\hline Base-country policy rate & $\begin{array}{c}0.56^{* *} \\
(0.04)\end{array}$ & $\begin{array}{l}0.32^{*} \\
(0.06)\end{array}$ & $\begin{array}{c}0.30^{* *} \\
(0.05)\end{array}$ & $\begin{array}{l}0.38^{* * *} \\
(0.01)\end{array}$ & $\begin{array}{c}0.31^{* *} \\
(0.05)\end{array}$ & $\begin{array}{c}0.37^{* *} \\
(0.02)\end{array}$ & $\begin{array}{l}0.33^{* *} \\
(0.05)\end{array}$ \\
\hline$\times$ NFX (excl. reserves) & & $-0.77^{* * *}$ & & & & & \\
\hline$\times \mathrm{NFX}($ excl. reserves $) \times \mathrm{I}(\mathrm{NFX} \geq 0)$ & & & $\begin{array}{c}-0.73^{* * *} \\
(0.00)\end{array}$ & & & & \\
\hline$\times$ NFX $($ excl. reserves $) \times \mathrm{I}(\mathrm{NFX}<0)$ & & & $-0.77^{* * *}$ & & & & \\
\hline$\times$ Non-debt NFX & & & & $\begin{array}{c}-0.23 \\
(0.17)\end{array}$ & $\begin{array}{c}-0.32^{*} \\
(0.07)\end{array}$ & $\begin{array}{c}-0.23 \\
(0.17)\end{array}$ & $\begin{array}{c}-0.36^{* *} \\
(0.04)\end{array}$ \\
\hline$\times$ Debt NFX & & & & $\begin{array}{c}-0.54^{* * *} \\
(0.00)\end{array}$ & & & \\
\hline$\times$ Debt NFX $\times \mathrm{I}(\mathrm{NFX} \geq 0)$ & & & & & $\begin{array}{c}-0.36 * * * \\
(0.00)\end{array}$ & & \\
\hline$\times$ Debt NFX $\times \mathrm{I}(\mathrm{NFX}<0)$ & & & & & $\begin{array}{l}-0.47^{* * * *} \\
(0.00)\end{array}$ & & \\
\hline$\times$ Base-country-currency debt NFX & & & & & & $\begin{array}{c}-0.23 \\
(0.16)\end{array}$ & \\
\hline$\times$ Base-country-currency debt $\mathrm{NFX} \times \mathrm{I}(\mathrm{NFX} \geq 0)$ & & & & & & & $\begin{array}{l}0.05 \\
(0.94)\end{array}$ \\
\hline$\times$ Base-country-currency debt NFX $\times \mathrm{I}(\mathrm{NFX}<0)$ & & & & & & & $\begin{array}{c}-0.48^{* *} \\
(0.02)\end{array}$ \\
\hline$\times$ Non-base-country-currency debt NFX & & & & & & $\begin{array}{c}-0.37^{* * *} \\
(0.01)\end{array}$ & \\
\hline$\times$ Non-base-country-currency debt NFX $\times \mathrm{I}(\mathrm{NFX} \geq 0)$ & & & & & & & $\underset{(0.33)}{-0.41}$ \\
\hline$\times$ Non-base-country-currency debt $\mathrm{NFX} \times \mathrm{I}(\mathrm{NFX}<0)$ & & & & & & & $\begin{array}{c}-0.40^{* * *} \\
(0.00)\end{array}$ \\
\hline R-squared (within) & 0.05 & 0.08 & 0.10 & 0.09 & 0.09 & 0.09 & 0.09 \\
\hline Observations & 1736 & 1622 & 1622 & 1622 & 1622 & 1622 & 1622 \\
\hline Countries & 38 & 36 & 36 & 36 & 36 & 36 & 36 \\
\hline
\end{tabular}

$p$-values in parentheses

Driscoll-Kraay robust standard errors. Coefficient estimates of Taylor-rule fundamentals not reported.

${ }^{*} p<0.1,{ }^{* *} p<0.05,{ }^{* * *} p<0.01$

Table 12: Accounting for asymmetries in base-country policy rate changes under the financial channel of exchange rates and the trilemma, using conventional policy rates

\begin{tabular}{|c|c|c|c|c|}
\hline & (1) & $(2)$ & $(3)$ & $(4)$ \\
\hline Base-country policy rate & $\begin{array}{c}0.56^{* *} \\
(0.04)\end{array}$ & & & \\
\hline Base-country policy rate $\times \mathrm{I}\left(\Delta i_{b_{i}, t}^{p} \geq 0\right)$ & & $\begin{array}{c}0.59^{* *} \\
(0.04)\end{array}$ & $\begin{array}{l}0.33^{*} \\
(0.06)\end{array}$ & $\begin{array}{l}-0.11 \\
(0.73)\end{array}$ \\
\hline Base-country policy rate $\times \mathrm{I}\left(\Delta i_{b_{i}, t}^{p} \geq 0\right) \times$ Net FX exposure & & & $\begin{array}{l}-0.80^{* * *} \\
(0.00)\end{array}$ & \\
\hline Base-country policy rate $\times \mathrm{I}\left(\Delta i_{b_{i}, t}^{p} \geq 0\right) \times$ Net FX exposure $\times \mathrm{I}(\mathrm{NFX} \geq 0)$ & & & & $\begin{array}{l}0.01 \\
(0.98)\end{array}$ \\
\hline Base-country policy rate $\times \mathrm{I}\left(\Delta i_{b_{i}, t}^{p} \geq 0\right) \times$ Net FX exposure $\times \mathrm{I}(\mathrm{NFX}<0)$ & & & & $\begin{array}{l}-2.01^{* * *} \\
(0.01)\end{array}$ \\
\hline Base-country policy rate $\times \mathrm{I}\left(\Delta i_{b_{i}, t}^{p}<0\right)$ & & $\begin{array}{c}-3.88^{*} \\
(0.08)\end{array}$ & $\begin{array}{c}-2.04^{*} \\
(0.06)\end{array}$ & $\begin{array}{c}-1.87 \\
(0.19)\end{array}$ \\
\hline Base-country policy rate $\times \mathrm{I}\left(\Delta i_{b_{i}, t}^{p}<0\right) \times$ Net FX exposure & & & $\begin{array}{l}0.12 \\
(0.85)\end{array}$ & \\
\hline Base-country policy rate $\times \mathrm{I}\left(\Delta i_{b_{i}, t}^{p}<0\right) \times$ Net FX exposure $\times \mathrm{I}(\mathrm{NFX} \geq 0)$ & & & & $\begin{array}{l}0.57 \\
(0.36)\end{array}$ \\
\hline Base-country policy rate $\times \mathrm{I}\left(\Delta i_{b_{i}, t}^{p}<0\right) \times$ Net FX exposure $\times \mathrm{I}(\mathrm{NFX}<0)$ & & & & $\begin{array}{l}0.50 \\
(0.83)\end{array}$ \\
\hline R-squared (within) & 0.05 & 0.06 & 0.09 & 0.10 \\
\hline Observations & 1736 & 1736 & 1622 & 1622 \\
\hline Countries & 38 & 38 & 36 & 36 \\
\hline
\end{tabular}

$p$-values in parentheses

Driscoll-Kraay robust standard errors. Coefficient estimates of Taylor-rule fundamentals not reported.

${ }^{*} p<0.1,{ }^{* *} p<0.05,{ }^{* * *} p<0.01$ 
Table 13: The financial channel of exchange rates and the trilemma, only EMEs

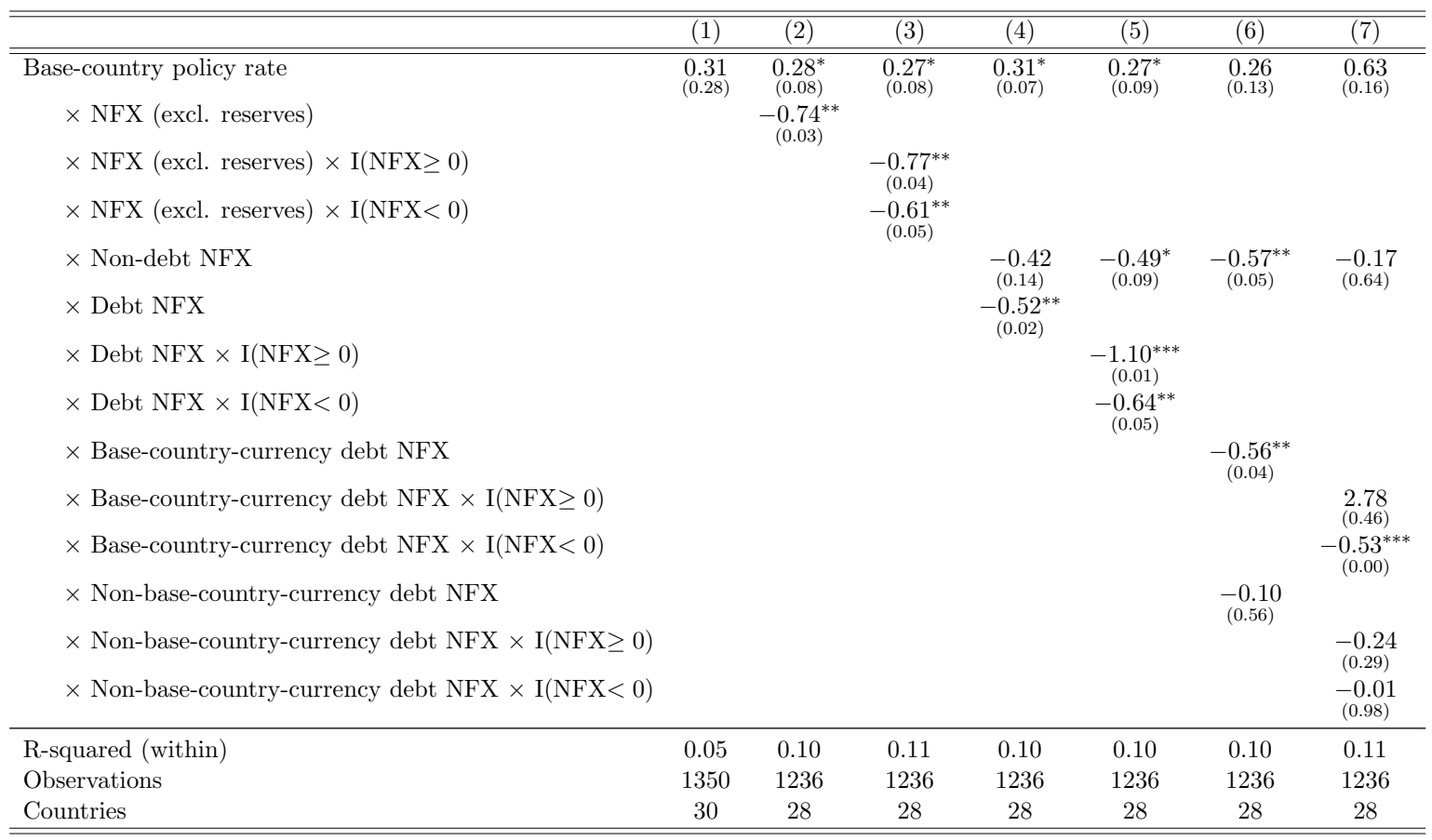

$p$-values in parentheses

Driscoll-Kraay robust standard errors. Coefficient estimates of Taylor-rule fundamentals not reported.

${ }^{*} p<0.1,{ }^{* *} p<0.05,{ }^{* * *} p<0.01$

Table 14: Accounting for asymmetries in base-country policy rate changes under the financial channel of exchange rates and the trilemma, only EMEs

\begin{tabular}{|c|c|c|c|c|}
\hline & $(1)$ & $(2)$ & $(3)$ & (4) \\
\hline Base-country policy rate & $\begin{array}{l}0.31 \\
(0.28)\end{array}$ & & & \\
\hline Base-country policy rate $\times \mathrm{I}\left(\Delta i_{b_{i}, t}^{p} \geq 0\right)$ & & $\begin{array}{l}0.35 \\
(0.23)\end{array}$ & $\begin{array}{l}0.29^{*} \\
(0.08)\end{array}$ & $\begin{array}{l}-0.21 \\
(0.60)\end{array}$ \\
\hline Base-country policy rate $\times \mathrm{I}\left(\Delta i_{b_{i}, t}^{p} \geq 0\right) \times$ Net FX exposure & & & $\begin{array}{c}-0.77^{* *} \\
(0.03)\end{array}$ & \\
\hline Base-country policy rate $\times \mathrm{I}\left(\Delta i_{b_{i}, t}^{p} \geq 0\right) \times$ Net FX exposure $\times \mathrm{I}(\mathrm{NFX} \geq 0)$ & & & & $\begin{array}{c}-0.04 \\
(0.92)\end{array}$ \\
\hline Base-country policy rate $\times \mathrm{I}\left(\Delta i_{b_{i}, t}^{p} \geq 0\right) \times$ Net FX exposure $\times \mathrm{I}(\mathrm{NFX}<0)$ & & & & $\begin{array}{c}-2.34^{* *} \\
(0.05)\end{array}$ \\
\hline Base-country policy rate $\times \mathrm{I}\left(\Delta i_{b_{i}, t}^{p}<0\right)$ & & $\begin{array}{c}-3.83^{*} \\
(0.09)\end{array}$ & $\begin{array}{l}-1.37 \\
(0.32)\end{array}$ & $\begin{array}{c}-3.22 \\
(0.11)\end{array}$ \\
\hline Base-country policy rate $\times \mathrm{I}\left(\Delta i_{b_{i}, t}^{p}<0\right) \times$ Net FX exposure & & & $\begin{array}{l}0.67 \\
(0.70)\end{array}$ & \\
\hline Base-country policy rate $\times \mathrm{I}\left(\Delta i_{b_{i}, t}^{p}<0\right) \times$ Net FX exposure $\times \mathrm{I}(\mathrm{NFX} \geq 0)$ & & & & $\underset{(0.05)}{20.18^{* *}}$ \\
\hline Base-country policy rate $\times \mathrm{I}\left(\Delta i_{b_{i}, t}^{p}<0\right) \times$ Net FX exposure $\times \mathrm{I}(\mathrm{NFX}<0)$ & & & & $\begin{array}{l}-2.77 \\
(0.27)\end{array}$ \\
\hline R-squared (within) & 0.05 & 0.06 & 0.11 & 0.12 \\
\hline Observations & 1350 & 1350 & 1236 & 1236 \\
\hline Countries & 30 & 30 & 28 & 28 \\
\hline
\end{tabular}

$p$-values in parentheses

Driscoll-Kraay robust standard errors. Coefficient estimates of Taylor-rule fundamentals not reported.

${ }^{*} p<0.1,{ }^{* *} p<0.05,{ }^{* * *} p<0.01$ 
Table 15: The financial channel of exchange rates and the trilemma, no CHE and SGP

\begin{tabular}{|c|c|c|c|c|c|c|c|}
\hline & $(1)$ & $(2)$ & $(3)$ & $(4)$ & $(5)$ & $(6)$ & $(7)$ \\
\hline Base-country policy rate & $\begin{array}{l}0.52^{*} \\
(0.06)\end{array}$ & $\begin{array}{c}0.49^{* * *} \\
(0.00)\end{array}$ & $\begin{array}{c}0.48^{* * *} \\
(0.00)\end{array}$ & $\begin{array}{c}0.50^{* * *} \\
(0.00)\end{array}$ & $\begin{array}{c}0.44^{* * *} \\
(0.00)\end{array}$ & $\begin{array}{c}0.46^{* * *} \\
(0.00)\end{array}$ & $\begin{array}{c}0.49^{* * *} \\
(0.00)\end{array}$ \\
\hline$\times$ NFX (excl. reserves) & & $\begin{array}{l}-0.29^{* *} \\
(0.03)\end{array}$ & & & & & \\
\hline$\times \mathrm{NFX}($ excl. reserves $) \times \mathrm{I}(\mathrm{NFX} \geq 0)$ & & & $\begin{array}{c}-0.20^{* *} \\
(0.02)\end{array}$ & & & & \\
\hline$\times$ NFX $($ excl. reserves $) \times \mathrm{I}(\mathrm{NFX}<0)$ & & & $\begin{array}{c}-0.69^{* *} \\
(0.05)\end{array}$ & & & & \\
\hline$\times$ Non-debt NFX & & & & $\begin{array}{c}-0.17 \\
(0.17)\end{array}$ & $\begin{array}{c}-0.21^{* *} \\
(0.05)\end{array}$ & $\begin{array}{c}-0.15 \\
(0.19)\end{array}$ & $\begin{array}{c}-0.21^{* *} \\
(0.05)\end{array}$ \\
\hline$\times$ Debt NFX & & & & $\begin{array}{l}-0.30^{* * *} \\
(0.01)\end{array}$ & & & \\
\hline$\times$ Debt NFX $\times \mathrm{I}(\mathrm{NFX} \geq 0)$ & & & & & $\begin{array}{c}-0.02 \\
(0.53)\end{array}$ & & \\
\hline$\times$ Debt NFX $\times \mathrm{I}(\mathrm{NFX}<0)$ & & & & & $\begin{array}{l}-0.52^{* * *} \\
(0.00)\end{array}$ & & \\
\hline$\times$ Base-country-currency debt NFX & & & & & & $\begin{array}{c}-0.02 \\
(0.84)\end{array}$ & \\
\hline$\times$ Base-country-currency debt $\mathrm{NFX} \times \mathrm{I}(\mathrm{NFX} \geq 0)$ & & & & & & & $\begin{array}{l}0.19 \\
(0.25)\end{array}$ \\
\hline$\times$ Base-country-currency debt $\mathrm{NFX} \times \mathrm{I}(\mathrm{NFX}<0)$ & & & & & & & $\begin{array}{c}-0.54^{* * *} \\
(0.01)\end{array}$ \\
\hline$\times$ Non-base-country-currency debt NFX & & & & & & $\begin{array}{l}-0.30^{* * *} \\
(0.01)\end{array}$ & \\
\hline$\times$ Non-base-country-currency debt NFX $\times \mathrm{I}(\mathrm{NFX} \geq 0)$ & & & & & & & $\begin{array}{c}-0.32 \\
(0.19)\end{array}$ \\
\hline$\times$ Non-base-country-currency debt $\mathrm{NFX} \times \mathrm{I}(\mathrm{NFX}<0)$ & & & & & & & $\begin{array}{c}-0.37^{* * *} \\
(0.00)\end{array}$ \\
\hline R-squared (within) & 0.05 & 0.08 & 0.09 & 0.08 & 0.09 & 0.08 & 0.10 \\
\hline Observations & 1701 & 1587 & 1587 & 1587 & 1587 & 1587 & 1587 \\
\hline Countries & 36 & 34 & 34 & 34 & 34 & 34 & 34 \\
\hline
\end{tabular}

Driscoll-Kraay robust standard errors. Coefficient estimates of Taylor-rule fundamentals not reported.

${ }^{*} p<0.1,{ }^{* *} p<0.05,{ }^{* * *} p<0.01$

Table 16: Accounting for asymmetries in base-country policy rate changes under the financial channel of exchange rates and the trilemma, no CHE and SGP

\begin{tabular}{|c|c|c|c|c|}
\hline & (1) & $(2)$ & $(3)$ & $(4)$ \\
\hline Base-country policy rate & $\begin{array}{l}0.52^{*} \\
(0.06)\end{array}$ & & & \\
\hline Base-country policy rate $\times \mathrm{I}\left(\Delta i_{b_{i}, t}^{p} \geq 0\right)$ & & $\begin{array}{c}0.59^{* *} \\
(0.04)\end{array}$ & $\begin{array}{c}0.50^{* * *} \\
(0.00)\end{array}$ & $\begin{array}{c}-0.08 \\
(0.84)\end{array}$ \\
\hline Base-country policy rate $\times \mathrm{I}\left(\Delta i_{b_{i}, t}^{p} \geq 0\right) \times$ Net FX exposure & & & $\begin{array}{l}-0.30^{* *} \\
(0.04)\end{array}$ & \\
\hline Base-country policy rate $\times \mathrm{I}\left(\Delta i_{b_{i}, t}^{p} \geq 0\right) \times$ Net FX exposure $\times \mathrm{I}(\mathrm{NFX} \geq 0)$ & & & & $\begin{array}{l}0.14 \\
(0.48)\end{array}$ \\
\hline Base-country policy rate $\times \mathrm{I}\left(\Delta i_{b_{i}, t}^{p} \geq 0\right) \times$ Net FX exposure $\times \mathrm{I}(\mathrm{NFX}<0)$ & & & & $\begin{array}{c}-1.29^{* *} \\
(0.05)\end{array}$ \\
\hline Base-country policy rate $\times \mathrm{I}\left(\Delta i_{b_{i}, t}^{p}<0\right)$ & & $\begin{array}{l}-2.42 \\
(0.19)\end{array}$ & $\begin{array}{c}-0.96 \\
(0.30)\end{array}$ & $\begin{array}{l}-1.33 \\
(0.45)\end{array}$ \\
\hline Base-country policy rate $\times \mathrm{I}\left(\Delta i_{b_{i}, t}^{p}<0\right) \times$ Net FX exposure & & & $\begin{array}{l}1.04 \\
(0.28)\end{array}$ & \\
\hline Base-country policy rate $\times \mathrm{I}\left(\Delta i_{b_{i}, t}^{p}<0\right) \times$ Net FX exposure $\times \mathrm{I}(\mathrm{NFX} \geq 0)$ & & & & $\begin{array}{l}1.31 \\
(0.40)\end{array}$ \\
\hline Base-country policy rate $\times \mathrm{I}\left(\Delta i_{b_{i}, t}^{p}<0\right) \times$ Net FX exposure $\times \mathrm{I}(\mathrm{NFX}<0)$ & & & & $\begin{array}{l}0.38 \\
(0.79)\end{array}$ \\
\hline R-squared (within) & 0.05 & 0.05 & 0.09 & 0.10 \\
\hline Observations & 1701 & 1701 & 1587 & 1587 \\
\hline Countries & 36 & 36 & 34 & 34 \\
\hline
\end{tabular}




\section{B Figures}

Figure 1: Distribution of exchange rate regimes and capital control policy configurations in the sample
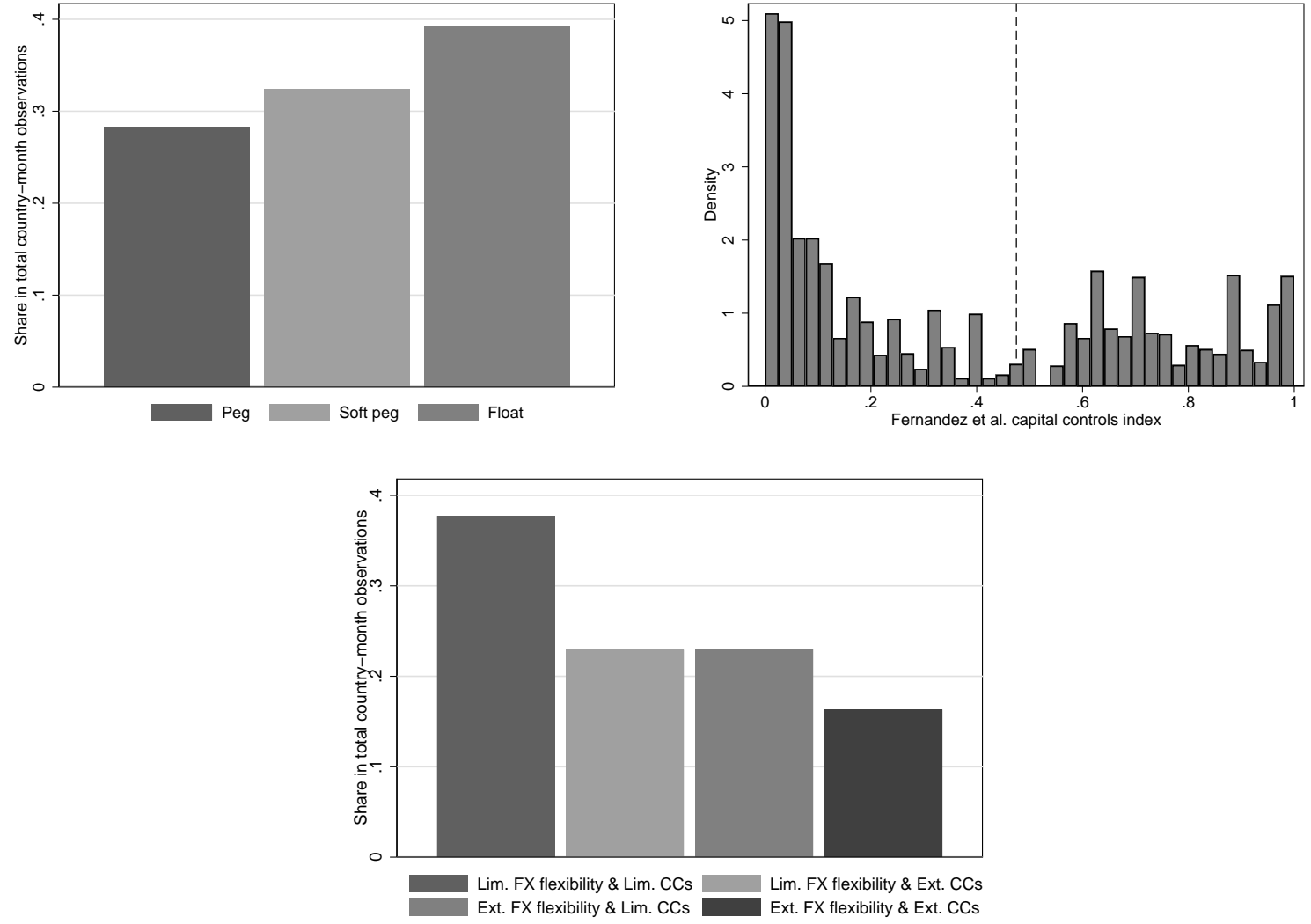

Note: The upper left-hand side panel displays the distribution of the exchange rate regime categories of Shambaugh (2004) in the sample. The upper right-hand side panel displays the distribution of the capital controls indicator of Fernandez et al. (2016): a value of zero represents the absence of capital controls, and a value of unity represents a completely closed capital account. The panel in the bottom row depicts the distribution of the policy configurations reflecting combinations of limited/extensive exchange rate flexibility and limited/extsenive capital controls. 
Figure 2: Conditional scatter plot of the relationship between changes in local policy rates and the level of the base-country policy rate
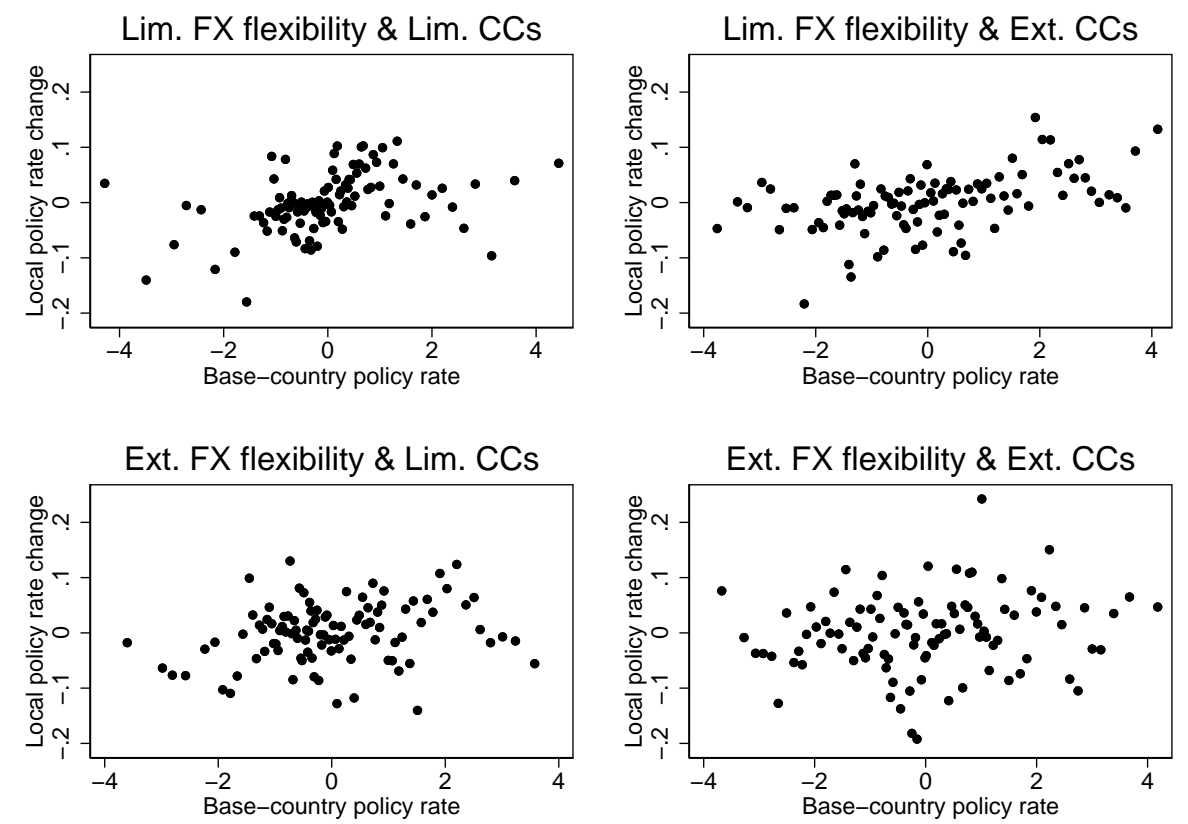

Note: The panels display conditional correlations between the base country shadow policy rate and changes in local monetary policy rates. Both variables represent residuals from regressions on all remaining right-hand side variables in the Taylor rule. For convenience in the regression the left-hand side variable is stated in first-differences rather than in levels as stated in Equation (4). The panels display bin scatter plots. 
Figure 3: Net foreign currency exposures

Net foreign currency exposures excluding foreign exchange reserves

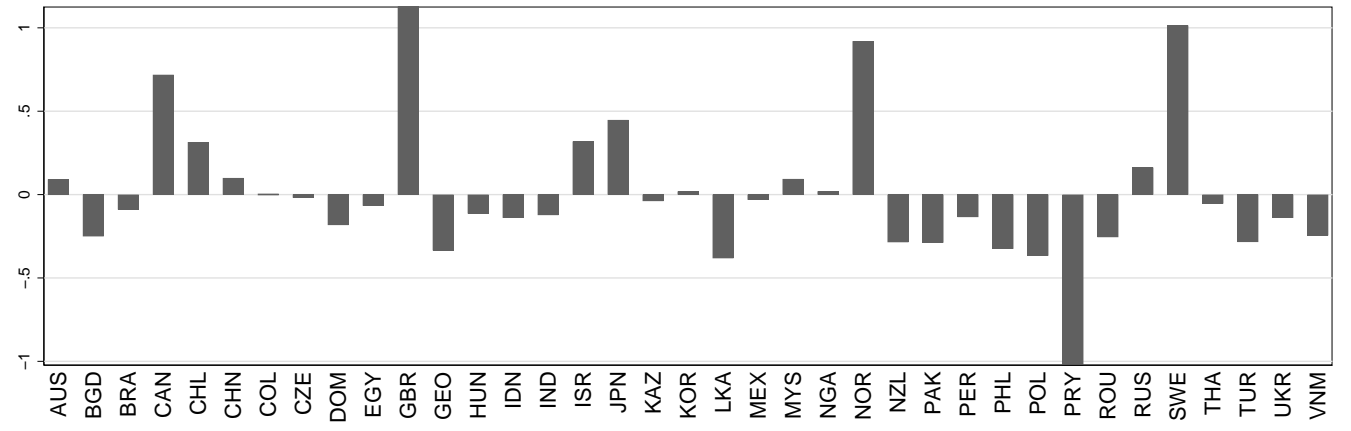

Debt net foreign currency exposures

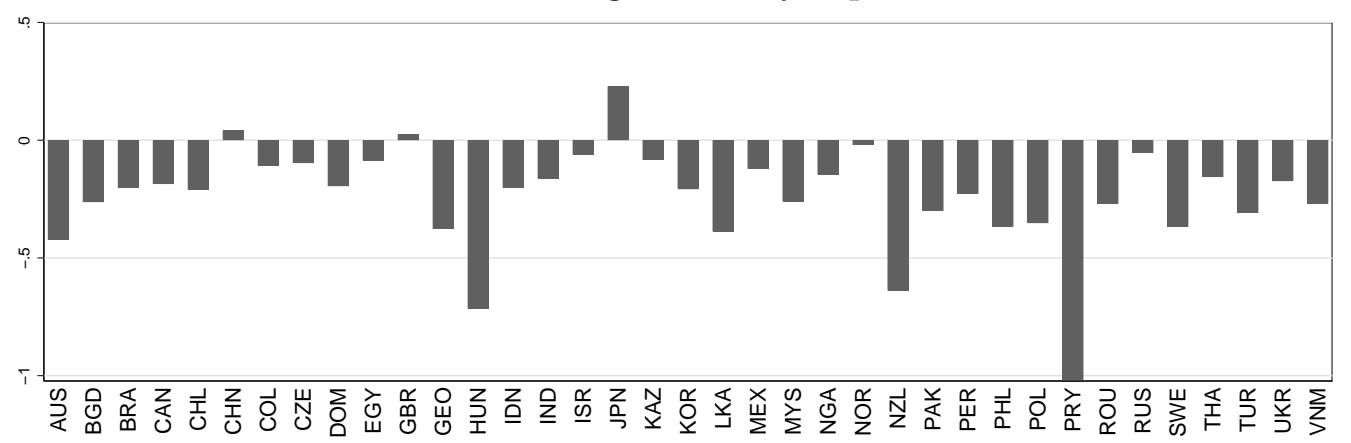

Non-debt net foreign currency exposures

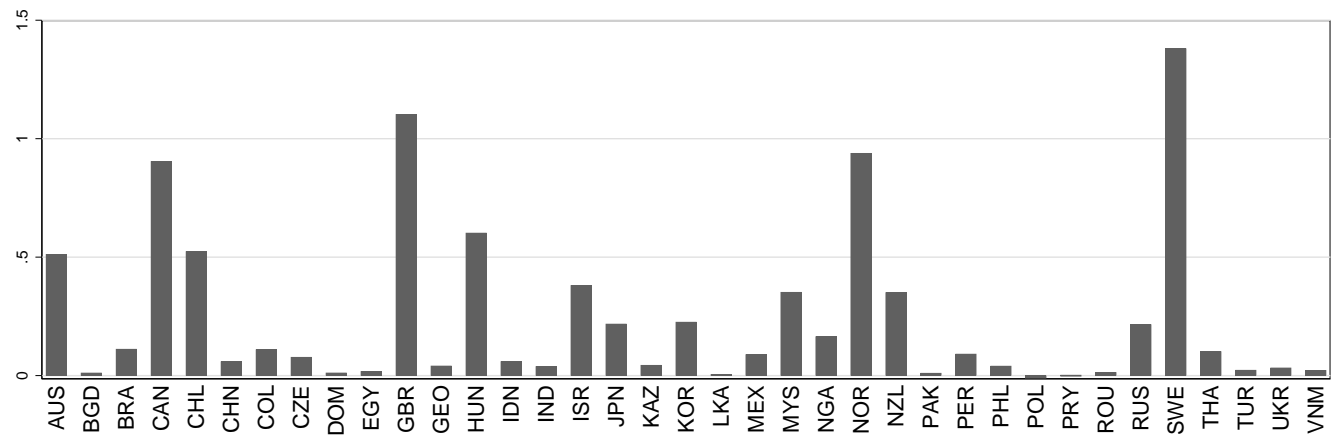

Note: The figure shows the net foreign currency exposure averaged over the sample period from 2002 to 2012. The data are taken from Lane and Shambaugh (2010) as well as Benetrix et al. (2015). The data are not shown for Singapore and Switzerland, which have very large positive values due to their property as financial centers. 


\section{Additional appendix}

\section{C.1 Relationship between CE forecasts and actual central bank projections}

Because the expectations of future real activity and inflation in Equation (4) are critical in order to differentiate between correlated policy rate changes in the local economy and the base country that are either due to common shocks or the lack of monetary policy autonomy, it is important to ensure that the $\mathrm{CE}$ forecasts we use are reliable proxies for the unobserved actual central bank expectations. To do so, we compare the CE forecasts with actual central bank projections for those central banks and time periods for which the latter are available. For this exercise, we draw on the dataset of central bank projections set up by Rülke (2012). The data include projections from the Bank of Canada, Bank of England, Bank of Japan, Bank of Mexico, Bundesbank, Central Bank of Argentina, Central Bank of Brazil, Central Bank of Chile, US Federal Reserve, Norges Bank, Reserve Bank of Australia, Reserve Bank of New Zealand, Reserve Bank of South Africa, Sveriges Riksbank, and Swiss National Bank. In order to compare the $\mathrm{CE}$ forecasts with the actual central bank projections we run the regression

$$
x_{i, t}^{e, c b, h}=a_{i}^{h}+b^{h} \cdot x_{i, t}^{e, c e, h}+e_{i}^{h},
$$

where $\boldsymbol{x}_{i t}^{e, c b, h}$ represents the actual central bank projection and $\boldsymbol{x}_{i t}^{e, c e, h}$ the CE forecast; we run the regression in Equation (C.1) for the current-period period- $t(h=0)$ and currentperiod period- $t+1$ one-year ahead forecast $(h=1)$ of GDP growth and inflation. Table 17 documents that CE forecasts are very closely related to the corresponding central bank projections for CPI inflation and GDP growth which are publicly available.

Table 17: Relationship between central bank projections and CE forecasts

\begin{tabular}{|c|c|c|c|c|}
\hline & $\begin{array}{c}(1) \\
y_{i t}^{e, c b} \\
\end{array}$ & $\begin{array}{c}(2) \\
y_{i, t+1}^{e, c b} \\
\end{array}$ & $\begin{array}{c}(3) \\
\pi_{i t}^{e, c b} \\
\end{array}$ & $\begin{array}{c}(4) \\
\pi_{i, t+1}^{e, c b} \\
\end{array}$ \\
\hline $\mathrm{CE}$ forecast & $\begin{array}{c}0.91^{* * *} \\
(0.00)\end{array}$ & $\begin{array}{c}0.96^{* * *} \\
(0.00)\end{array}$ & $\begin{array}{c}0.85^{* * *} \\
(0.00)\end{array}$ & $\begin{array}{c}0.67^{* * *} \\
(0.00)\end{array}$ \\
\hline Fixed effects & Yes & Yes & Yes & Yes \\
\hline R-squared & 0.94 & 0.83 & 0.94 & 0.91 \\
\hline Observations & 485 & 363 & 516 & 483 \\
\hline
\end{tabular}

\section{C.2 Estimation of exchange-rate pass through to consumer prices}

Following Campa and Goldberg (2005), we estimate short-run exchange rate pass-through to consumer prices based on the regression

$$
\Delta p_{i t}=\chi_{i}+\sum_{j=1}^{p_{i}} \sigma_{i j} \Delta s_{i t}+\sum_{j=1}^{q_{i}} \eta_{i j} \Delta p_{t}^{c o m m}+\nu_{i t},
$$


where $p_{i t}$ is the logarithm of local CPI, $s_{i t}$ is the bilateral exchange rate vis-à-vis the base country, and $p_{t}^{c o m m}$ is the logarithm of commodity prices. We then define $E \widehat{R P} T_{i}^{S R} \equiv$ $\sum_{j=1}^{3} \widehat{\sigma}_{i j}$ as the short-run pass-through estimate. For the long-run exchange rate pass-through to consumer prices we follow Hausmann et al. (2001) and estimate

$$
\Delta p_{i t}=\chi_{i}+\rho_{i}\left(p_{i t}-\gamma_{i} s_{i t}-\eta_{i} p_{t}^{c o m m}\right)+\sum_{j=1}^{p_{i}} \boldsymbol{\phi}_{i j}^{\prime} \Delta \boldsymbol{w}_{i t}+\nu_{i t}
$$

where we define $E \widehat{R P} T_{i}^{L R} \equiv \widehat{\gamma}_{i}$ as the long-run pass-through estimate. 
D Additional figures 
Figure 4: Data plots I
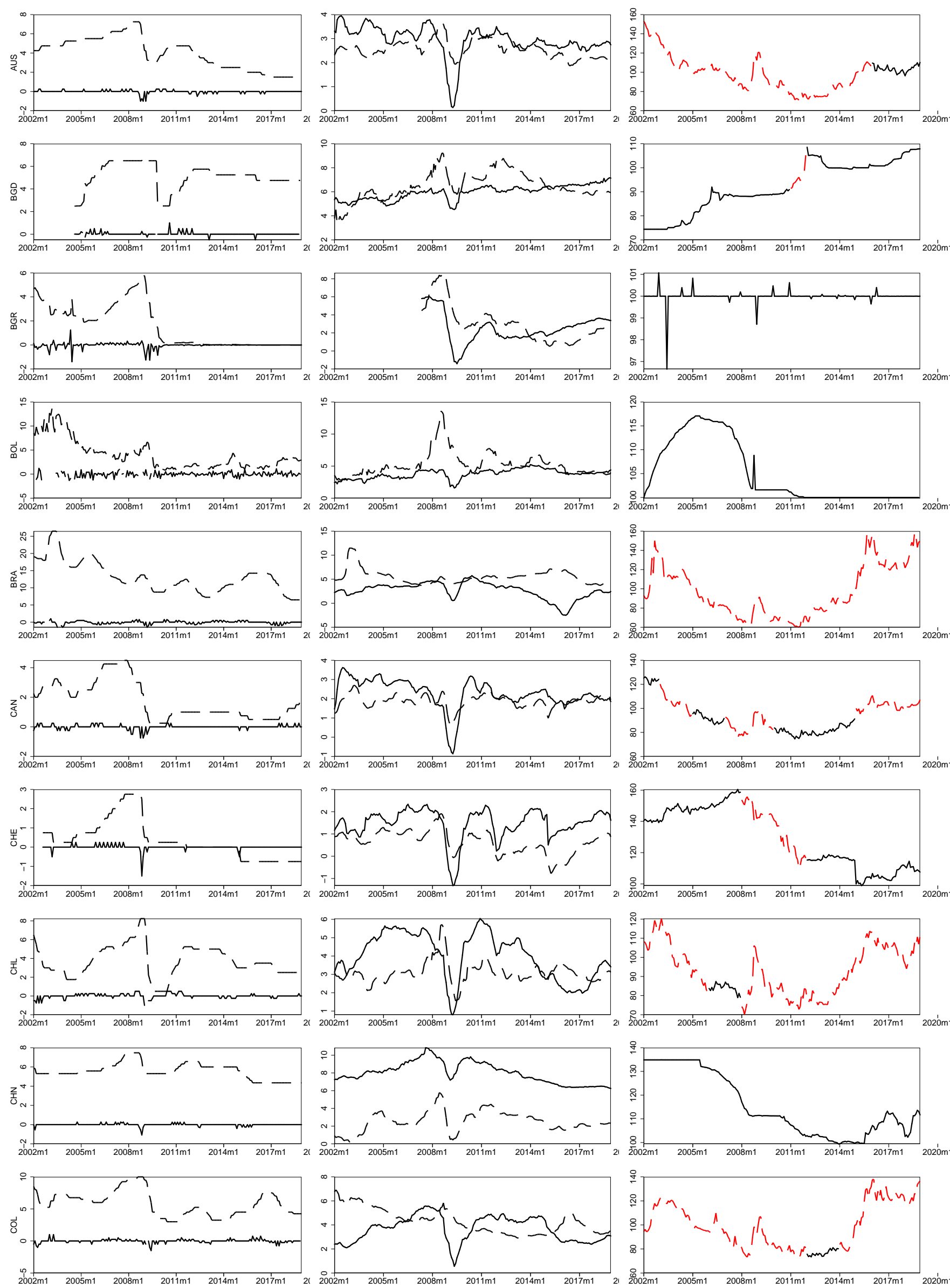
Figure 5: Data plots II
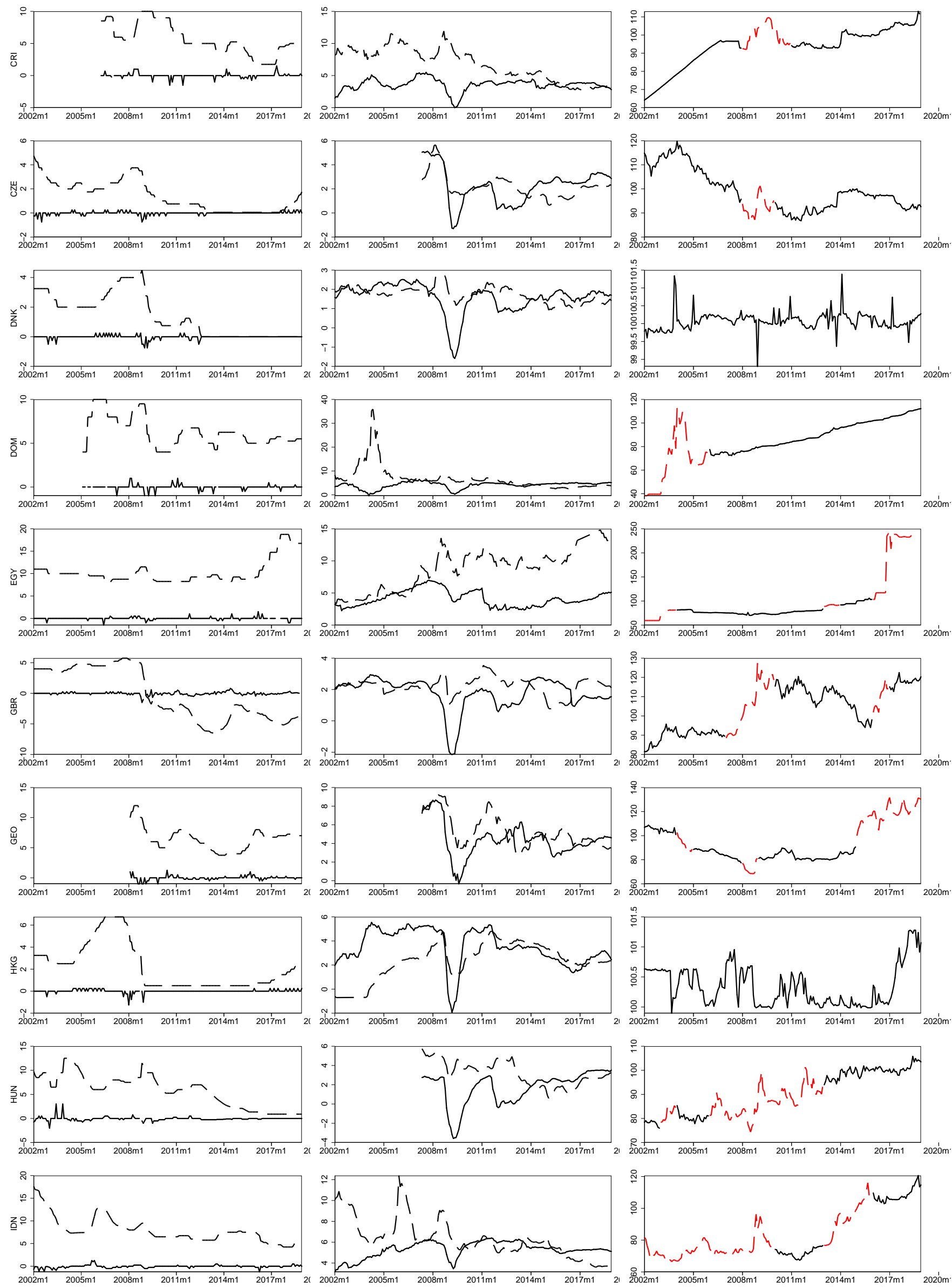

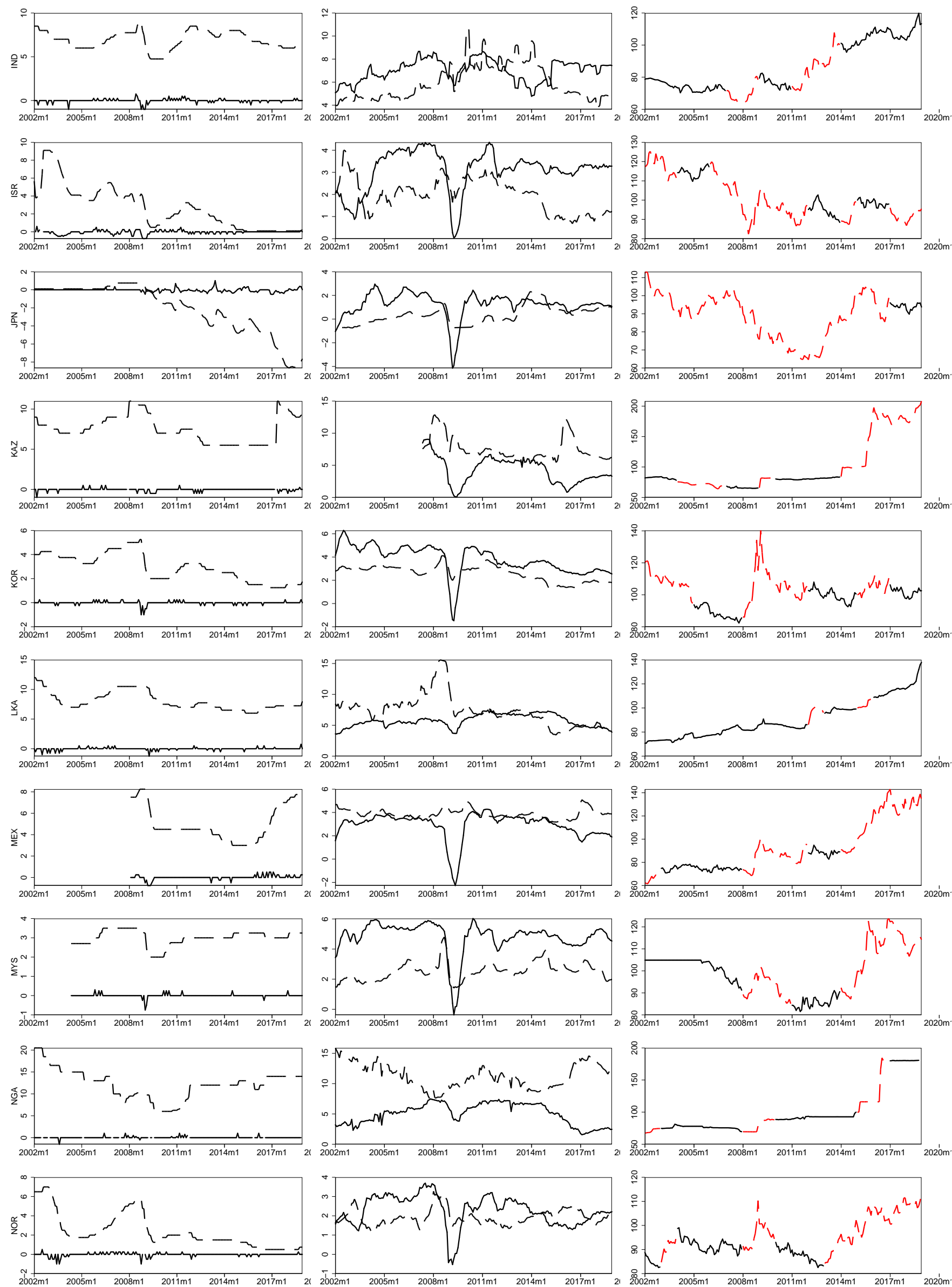
Figure 7: Data plots IV
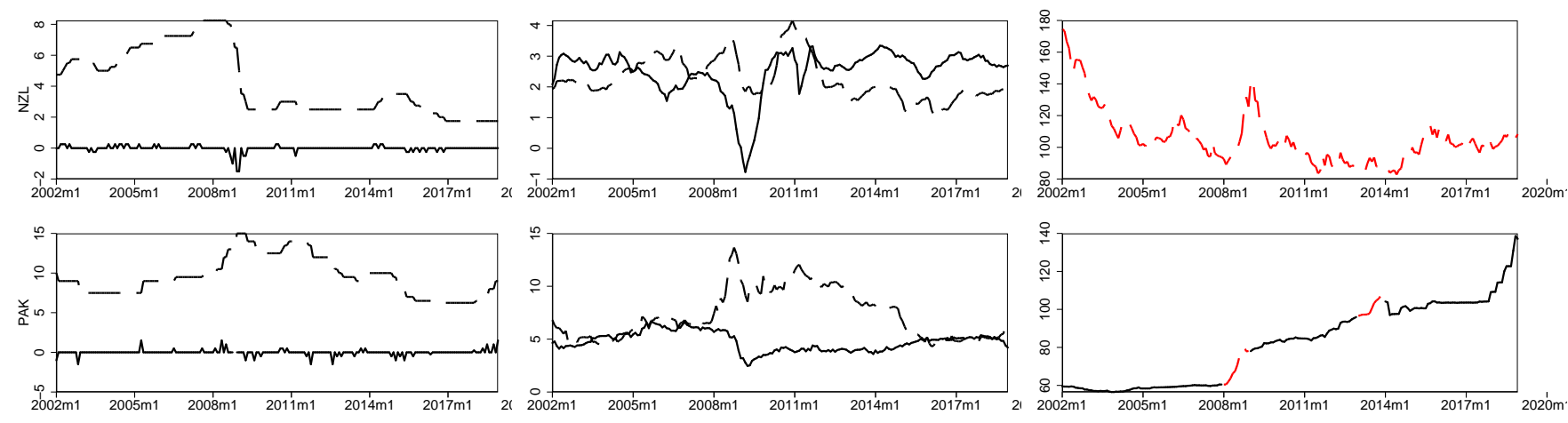

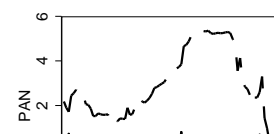

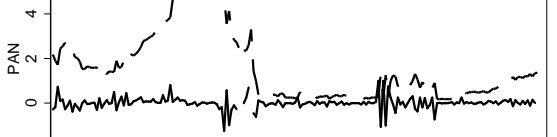

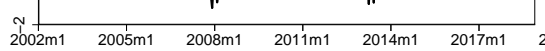
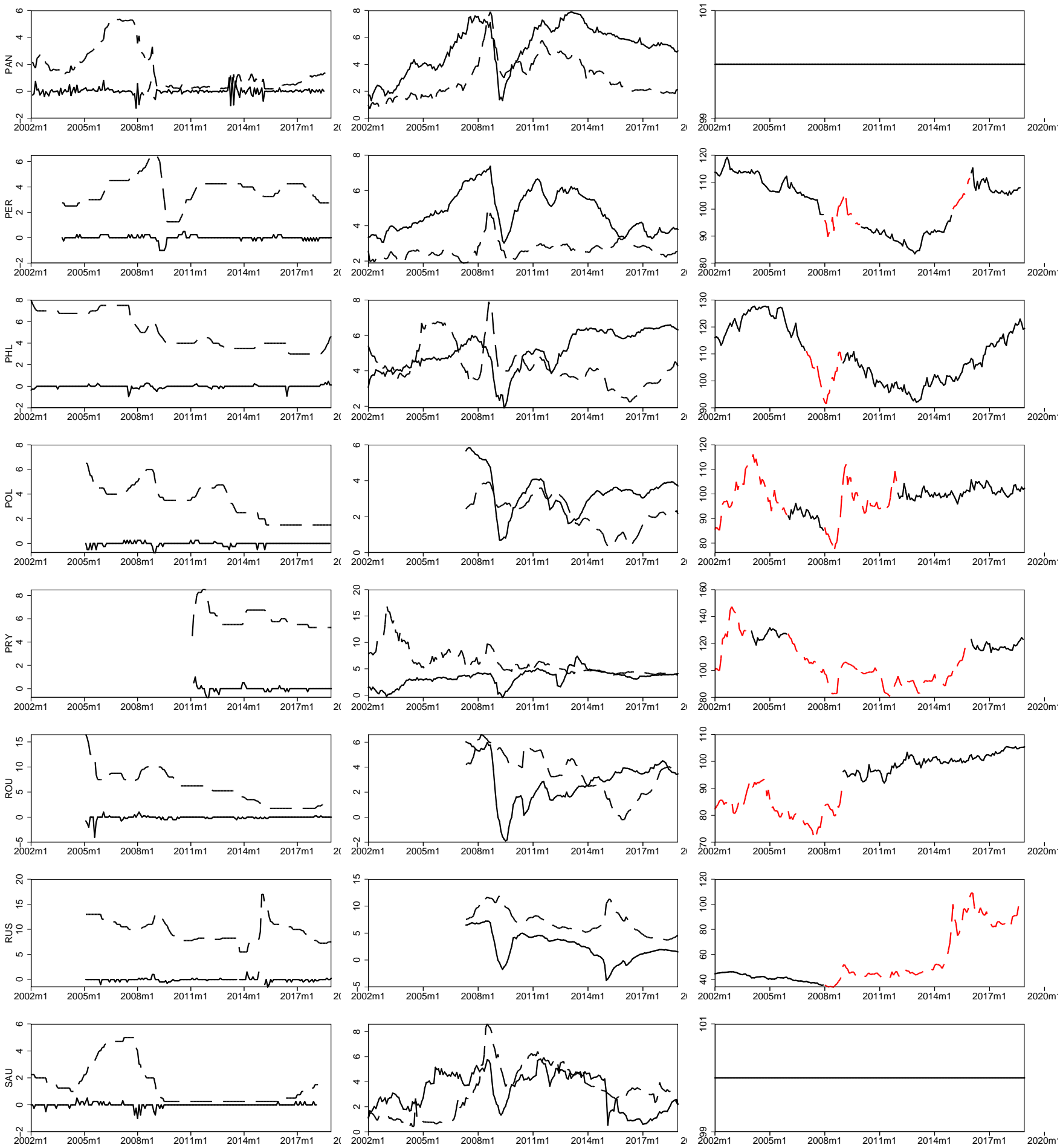
Figure 8: Data plots V
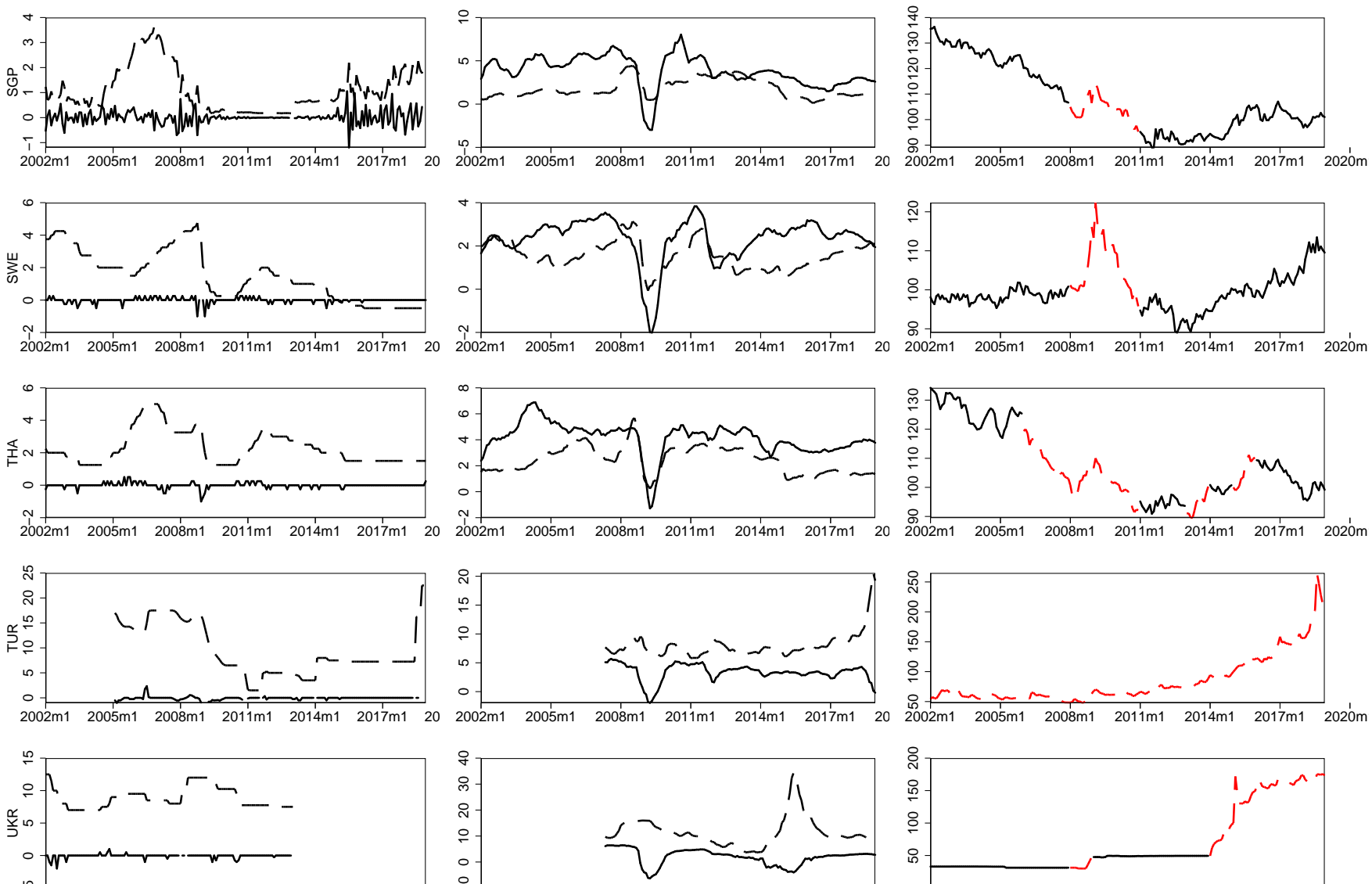

$2002 \mathrm{~m} 1 \quad 2005 \mathrm{~m} 1 \quad 2008 \mathrm{~m} 1 \quad 2011 \mathrm{~m} 1 \quad 2014 \mathrm{~m} 1 \quad 2017 \mathrm{~m} 1 \quad 20$
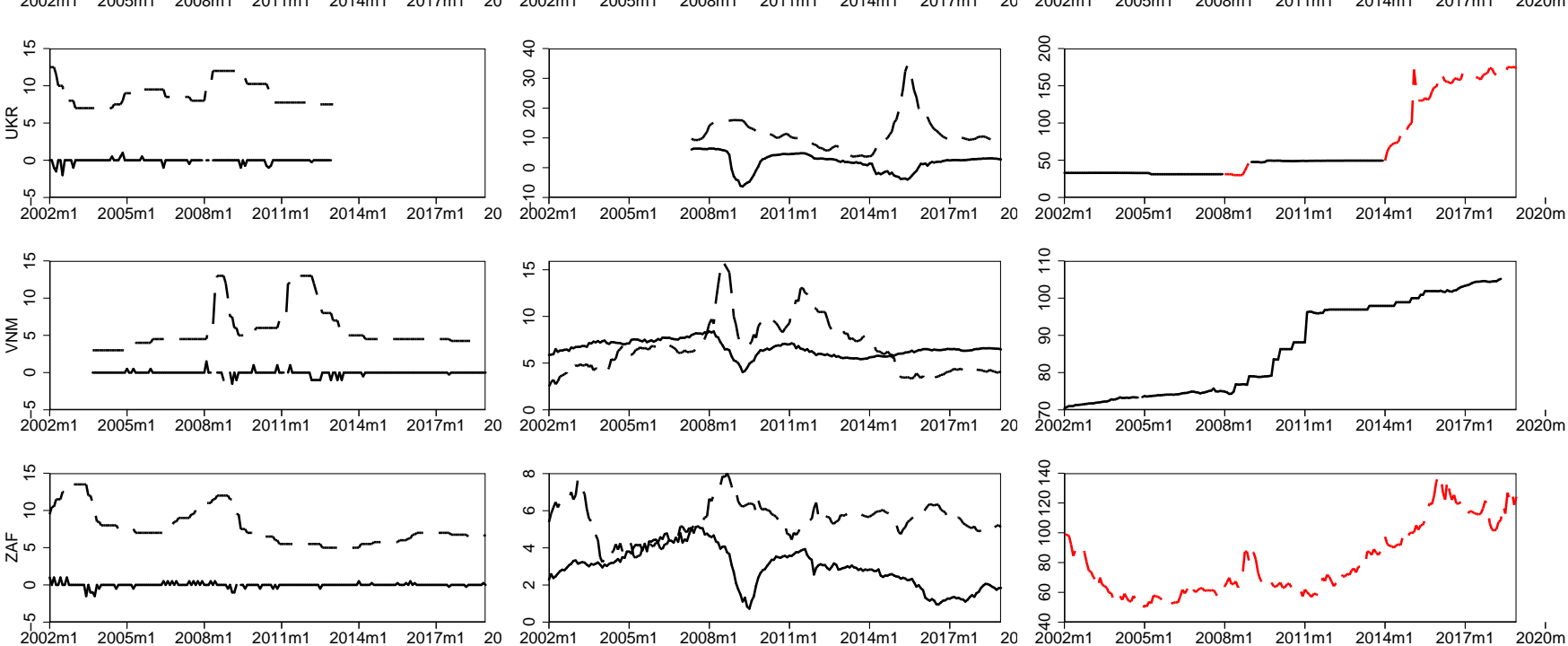
Figure 9: Evolution of policy configurations across economies

Lim. FXflex. \& lim. CCs Ext. FX flex. \& lim. CCs

Lim. FXflex. \& ext. CCs Ext. FX flex. \& ext. CCs

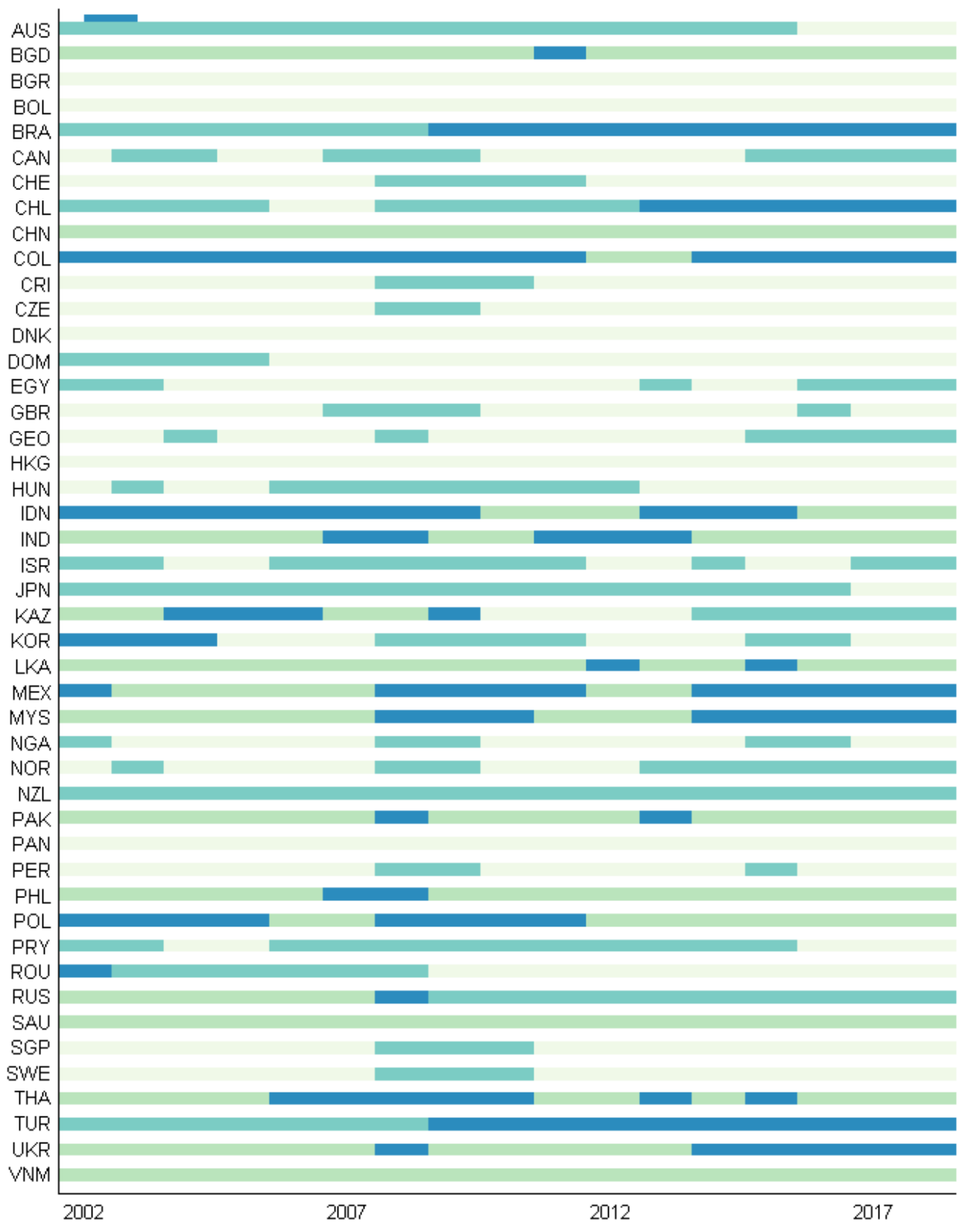


Figure 10: Share of sample period in different policy configurations across economies

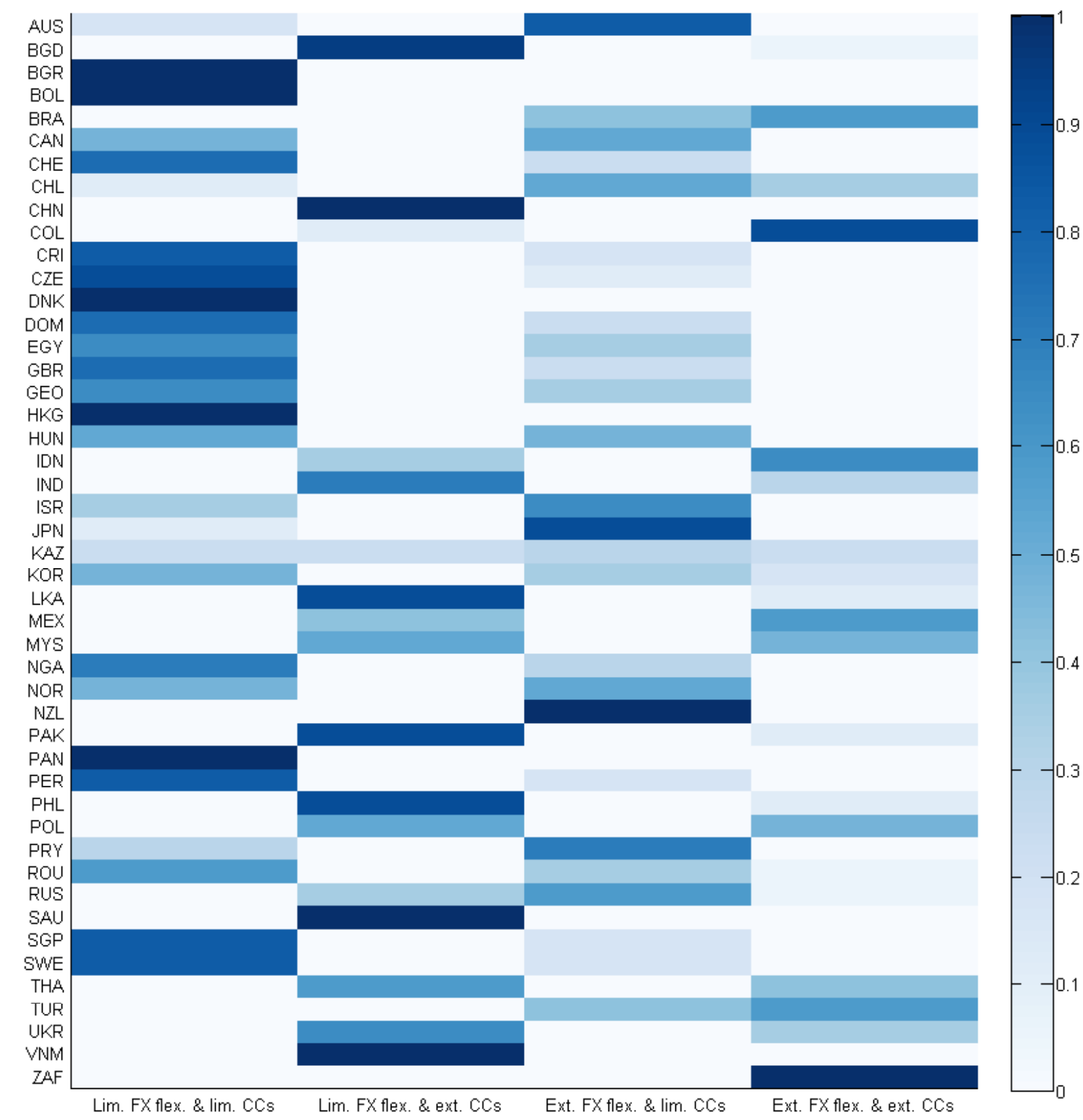


Figure 11: Data plots: Policy rates (I)
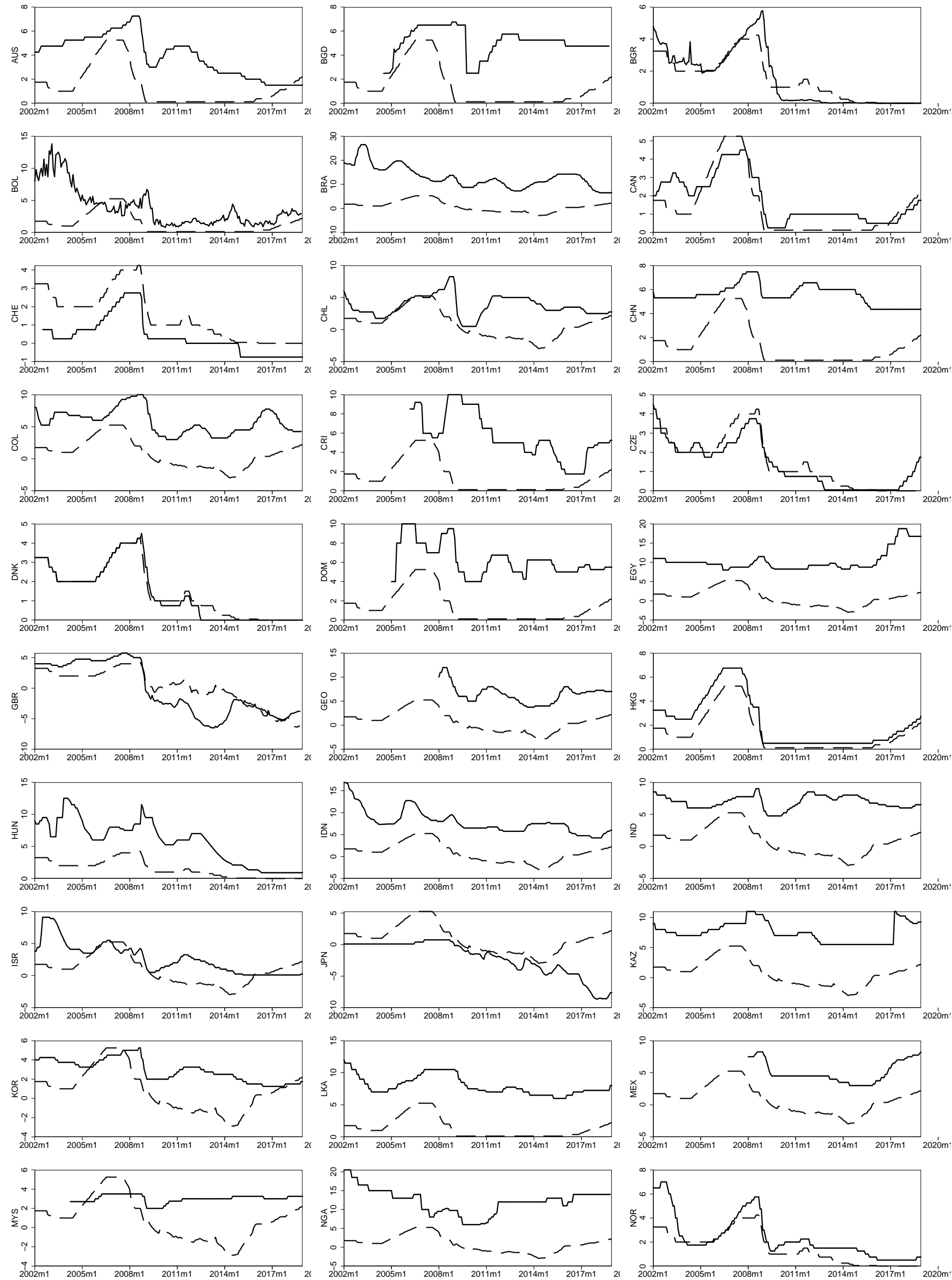
Figure 12: Data plots: Policy rates (II)
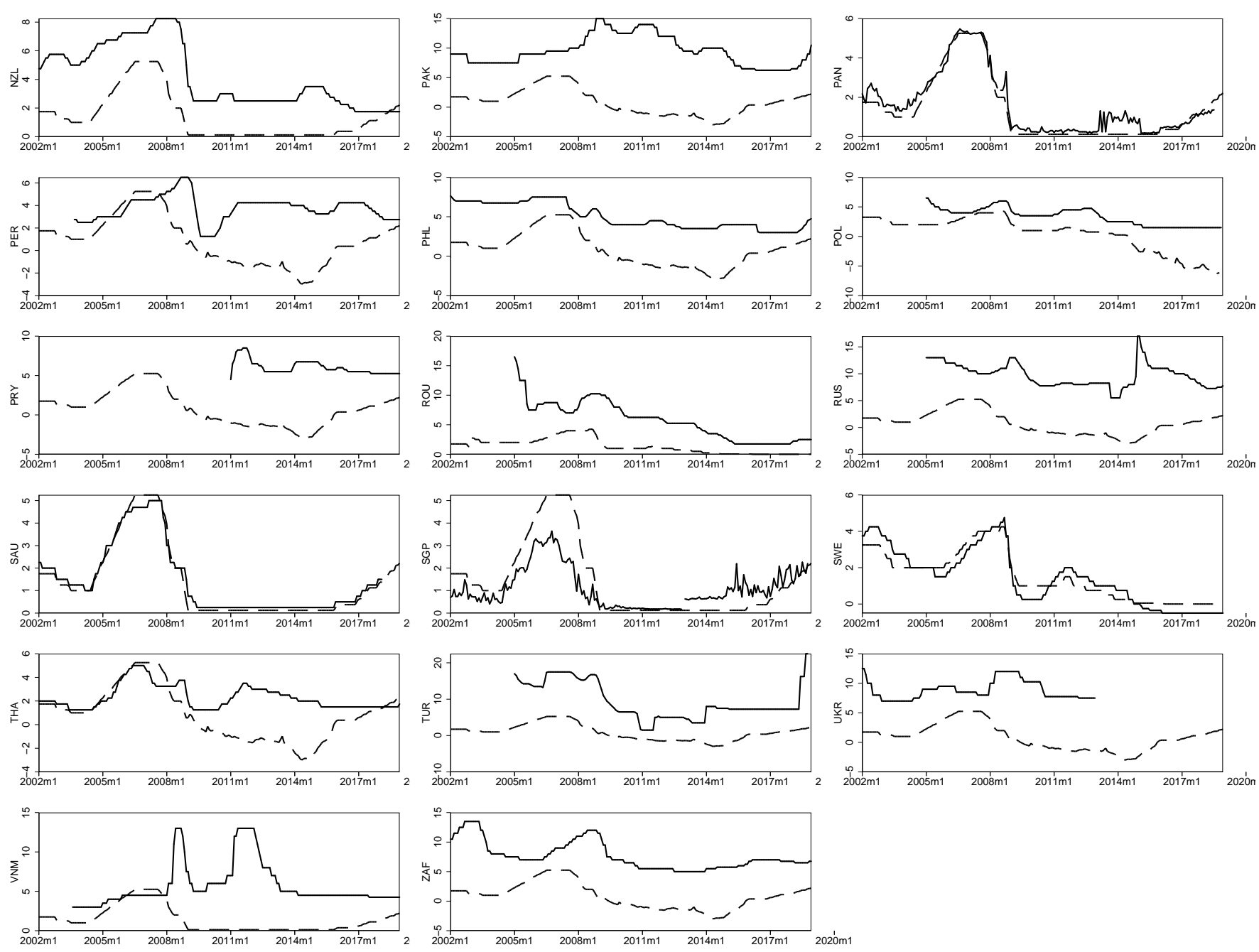


\section{E Additional robustness checks on baseline estimation results}

\section{E.1 Stability over time}

Row (2) in Table 18 presents the results for the estimation of Equation (4) for a sample that ends in 2015, which is the point in time until we have data for the capital controls indicator of Fernandez et al. (2016). Row (3) in Table 18 also presents the results for a sample that includes the time period from July 2007 to December 2009, which we drop in the baseline. The results for these two alternative sample periods are very similar to those from the baseline covering January 2002 to December 2018 and dropping July 2007 to December 2009.

Table 18: Alternative sample periods

\begin{tabular}{|c|c|c|c|c|}
\hline & $\begin{array}{l}\text { (1) } \\
\text { Lim. FX flex. } \\
\text { \& Lim. CCs }\end{array}$ & $\begin{array}{l}\text { Lim. } \stackrel{(2)}{\text { FX flex. }} \\
\text { \& Ext. CCs }\end{array}$ & $\begin{array}{l}\text { (3) } \\
\text { Ext. FX flex. } \\
\text { \& Lim. CCs }\end{array}$ & $\begin{array}{l}\text { (4) } \\
\text { Ext. } \mathrm{FX} \text { flex. } \\
\text { \& Ext. CCs } \\
\end{array}$ \\
\hline Baseline & $0.76(0.00)$ & $0.61(0.00)$ & $0.45(0.02)$ & $0.20(0.15)$ \\
\hline $02-15$ & $0.83(0.00)$ & $0.69(0.00)$ & $0.40(0.13)$ & $0.30(0.02)$ \\
\hline 02-18, no gap & $0.70(0.00)$ & $0.52(0.00)$ & $0.44(0.02)$ & $0.19(0.11)$ \\
\hline
\end{tabular}

Figures 13 and 14 display the evolution of the estimates of the sensitivity of the local to the base-country policy rate for recursively growing samples. Specifically, in Figure 13 the sample starting point is fixed at January 2002 and the sample end point is shifted forward one month at a time until it reaches December 2018. Similarly, in Figure 14 the sample end point is fixed at December 2018 and the sample starting point is shifted backward until it reaches January 2002. The solid black lines indicate that the estimates are statistically significant at the $90 \%$ significance level, while the red dashed lines indicate that the estimates are not statistically significant. The results suggest that our baseline estimates are generally not specific to starting the sample period in January 2002 or ending it in December 2018. Notice also that if one focuses on a sample that starts prior to 2002 one obtains misleading estimates in the sense that they are not representative for dynamics in the data in the 2000s in particular for economies with "extensive exchange rate flexibility" and "extensive capital controls".

\section{E.2 Allowing for cross-country coefficient heterogeneity}

In order to account for possible cross-country coefficient heterogeneity and prevent heterogeneity bias (Pesaran and Smith, 1995), we relax the homogeneity assumption in Equation (4) and estimate

$$
\Delta i_{i t}^{p}=\chi_{i}+\left(\rho_{i}-1\right) i_{i, t-1}^{p}+\left(1-\rho_{i}\right) \cdot\left(\boldsymbol{\phi}_{i}^{\prime} \boldsymbol{x}_{i, t}^{e}+\alpha_{i} i_{b_{i}, t}^{p}\right)+\sum_{\ell=1}^{p_{i}} \boldsymbol{\varphi}_{i \ell}^{\prime} \Delta \boldsymbol{w}_{i, t-\ell}+\nu_{i t},
$$


Figure 13: Estimation results from recursively varying the sample end point

Lim. FX flexibility \& Lim. CCs

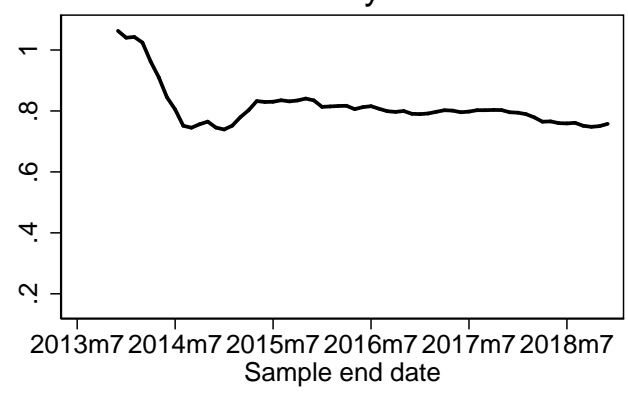

Ext. FX flexibility \& Lim. CCs

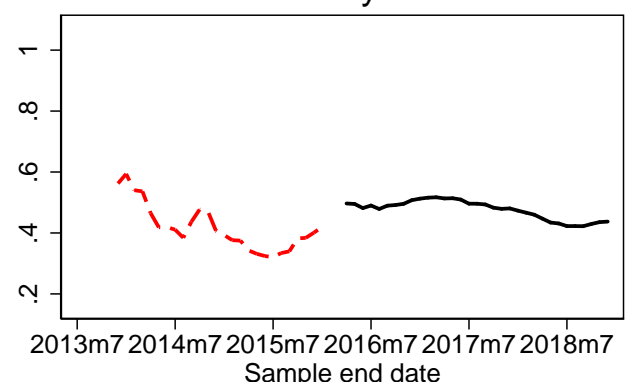

Lim. FX flexibility \& Ext. CCs

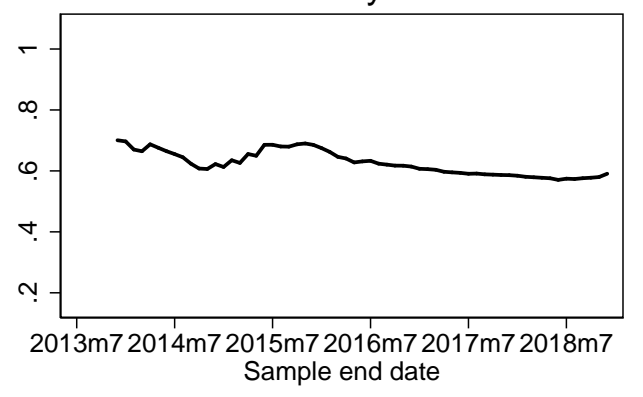

Ext. FX flexibility \& Ext. CCs

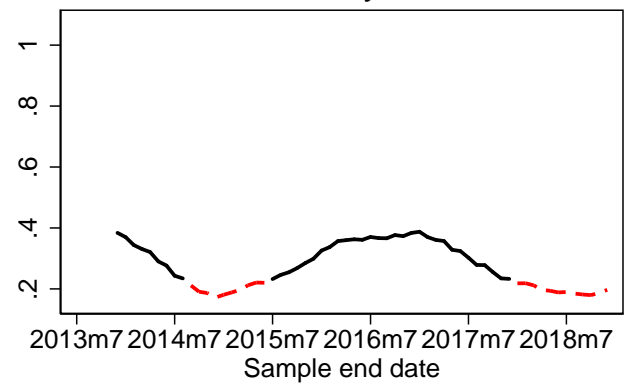

Note: The panels depict the evolution of the estimate for $\alpha_{j}$ for samples ending in the point in time indicated on the horizontal axis and starting in 2002 January. The black solid line indicates that the coefficient estimate is statistically significant at the $90 \%$ significance level, while the red dashed line indicates that it is not statistically significant. 
Figure 14: Estimation results from recursively varying the sample starting point

Lim. FX flexibility \& Lim. CCs

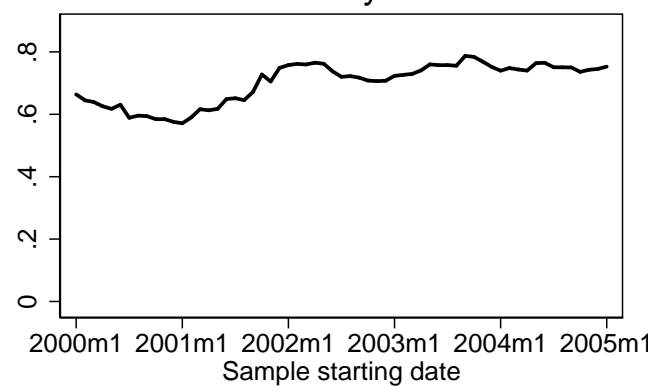

Ext. FX flexibility \& Lim. CCs

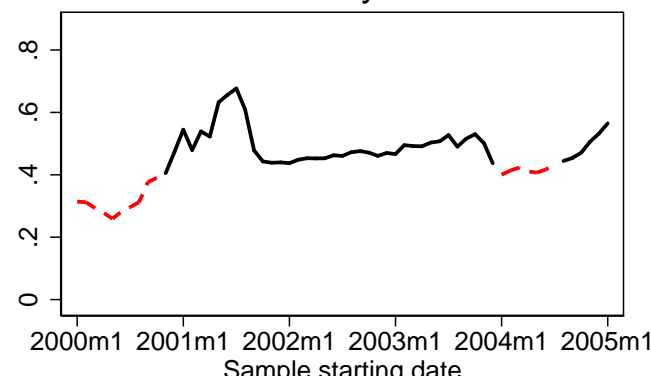

Lim. FX flexibility \& Ext. CCs

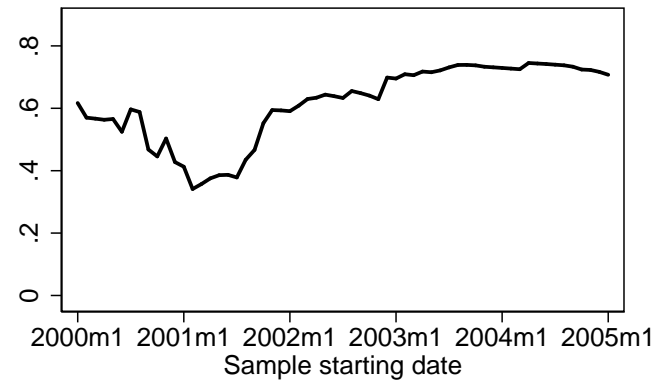

Ext. FX flexibility \& Ext. CCs

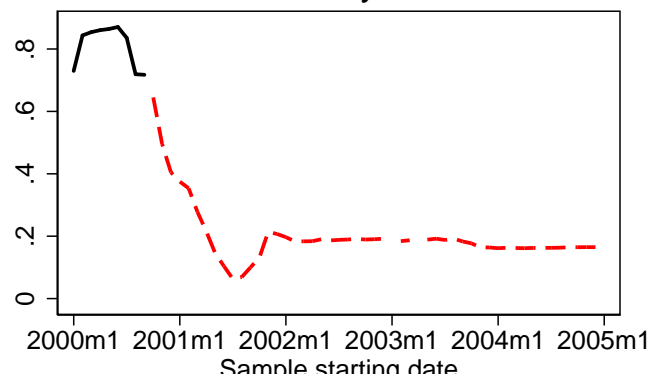

Note: The panels depict the evolution of the estimate for $\alpha_{j}$ for samples starting in the point in time indicated on the horizontal axis and running until December 2018. The black solid line indicates that the coefficient estimate is statistically significant at the $90 \%$ significance level, while the red dashed line indicates that it is not statistically significant. 
where $\boldsymbol{w}_{i t} \equiv\left(\boldsymbol{x}_{i, t}^{e \prime}, i_{b_{i}, t}^{p}\right)^{\prime}$ and which produces country-specific estimates of the sensitivity of local to base-country policy rates. We drop the global variables on the right-hand side in Equation (E.1) in order to save degrees of freedom in the country-specific time-series regressions, but include them in robustness checks below. We also only estimate Equation (E.1) for economies for which we have at least 60 consecutive time-series observations. Upon estimation of Equation (E.1), we examine the role of economies' capital controls and exchange rate flexibility configurations for the cross-country heterogeneity in the estimates of the sensitivity of local to base-country policy rates by estimating

$$
\begin{aligned}
\widehat{\alpha}_{i}= & \psi_{1} \cdot\left[I_{i}(\lim . \text { CCs }) \times I_{i}(\lim . \text { FX flexibility })\right] \\
& +\psi_{2} \cdot\left[\left(1-I_{i}(\lim . \text { CCs })\right) \times I_{i}(\lim . \text { FX flexibility })\right] \\
& +\psi_{3} \cdot\left[\left(I_{i}(\lim . \text { CCs })\right) \times\left(1-I_{i}(\lim . \text { FX flexibility })\right)\right] \\
& +\psi_{4} \cdot\left[\left(1-I_{i}(\lim . \text { CCs })\right) \times\left(1-I_{i}(\lim . \text { FX flexibility })\right)\right]+u_{i},
\end{aligned}
$$

where we define $I_{i}(\cdot) \equiv I\left[\sum_{t} T^{-1} I_{i t}(\cdot)>0.5\right]$; intuitively, we label a local economy as one with "extensive exchange rate flexibility" if this is what the economy featured for the largest part of the sample. Notice that estimating Equation (E.2) boils down to the mean-group estimator of Pesaran and Smith (1995). Finally, notice that we estimate Equation (E.2) using weighted least squares, using the inverse of the standard errors of the estimates $\widehat{\alpha}_{i}$ as weights.

The results for the estimation of Equation (E.2) are reported in Table 19. Column (1) reports the results from the baseline specification with $p_{i}=0$, column (2) from a specification in which we use country-specific optimal lag orders determined by the Akaike information criterion with a maximum lag order of one for all right-hand side variables, column (3) in which we consider only economies for which we could reject the null of no long-run levels relationship ${ }^{20}$, and in column (4) from a specification in which we add the global variables $z_{t}$ on the right-hand side of Equation (E.1). The results are consistent with those from the baseline.

\section{E.3 Alternative base-country policy rates}

Recall that in our baseline specification we consider the effects of the contemporaneous basecountry policy rate on the local policy rate. However, there might be lags in the transmission from the base to the local monetary policy stance, for example because in a given month the policy decision in the base-country is taken only after that in the local economy. In this case, our specification may underestimate the effect of base-country on local policy rates. In order to address this possibility, we replace the contemporaneous base-country policy rate in Equation (4) by its one-period lag. The results for the estimates of the sensitivity of the local to the base-country policy rate are reported in row (2) in Table 20 and are very similar

\footnotetext{
${ }^{20}$ To do so we consider the bounds test proposed in Pesaran et al. (2001). Specifically, we test the null $H: \rho_{i}-1<0$ by means of a $t$-test and, simultaneously, the null $H:\left[\boldsymbol{\phi}_{i}^{\prime}, \alpha_{i}\right]^{\prime}=\mathbf{0}$ by means of an $F$-test. Notice that the relevant test statistics have non-standard distributions due to the possibility of and uncertainty about non-stationarity of $\boldsymbol{w}_{i t}$ and $i_{i t}^{p}$.
} 
Table 19: Allowing for cross-country coefficient heterogeneity

\begin{tabular}{lcccc}
\hline \hline & $(1)$ & $(2)$ & $(3)$ & $(4)$ \\
& Baseline & Lags & LRR & Global \\
\hline$I_{i}$ (Lim. FX flexibility \& Lim. CCs) & $0.93^{* * *}$ & $0.84^{* * *}$ & $0.92^{* * *}$ & $0.90^{* * *}$ \\
& $(0.00)$ & $(0.00)$ & $(0.00)$ & $(0.00)$ \\
& & & & \\
$I_{i}$ (Lim. FX flexibility \& Ext. CCs) & $0.61^{* *}$ & $0.54^{* *}$ & $0.63^{* *}$ & $0.58^{* *}$ \\
& $(0.01)$ & $(0.04)$ & $(0.03)$ & $(0.02)$ \\
& & & & \\
$I_{i}$ (Ext. FX flexibility \& Lim. CCs) & $0.42^{* * *}$ & $0.35^{* *}$ & $0.41^{* *}$ & $0.37^{* *}$ \\
& $(0.00)$ & $(0.04)$ & $(0.02)$ & $(0.03)$ \\
& & & & \\
$I_{i}$ (Ext. FX flexibility \& Ext. CCs) & 0.29 & $0.44^{*}$ & 0.25 & 0.30 \\
& $(0.15)$ & $(0.08)$ & $(0.21)$ & $(0.17)$ \\
\hline R-squared & 0.82 & 0.75 & 0.82 & 0.78 \\
$\mathrm{~N}$ & 46 & 46 & 19 & 46 \\
\hline \hline$p$-values in parentheses & & & & \\
Robust standard errors. & & & & \\
${ }^{*} p<0.1,{ }^{* *} p<0.05,{ }^{* * *} p<0.01$ & & & & \\
& & & & \\
\end{tabular}

to those from the baseline.

Table 20: Alternative base-country policy rates

\begin{tabular}{lcccc}
\hline \hline & \multicolumn{1}{c}{$(1)$} & $(2)$ & $(3)$ & $(4)$ \\
& Lim. FX flex. & Lim. FX flex. & Ext. FX flex. & Ext. FX flex. \\
\& E Lim. CCs & \& Ext. CCs \\
\hline \hline Baseline & $0.76(0.00)$ & $0.61(0.00)$ & $0.45(0.02)$ & $0.20(0.15)$ \\
Lagged base rate & $0.74(0.00)$ & $0.60(0.00)$ & $0.40(0.05)$ & $0.20(0.15)$ \\
Conventional policy rate for all base-country and local rates & $0.86(0.00)$ & $0.85(0.00)$ & $0.33(0.13)$ & $0.45(0.01)$ \\
Shadow rate as base-country rate for all local economies & $0.51(0.00)$ & $0.57(0.00)$ & $0.28(0.12)$ & $0.21(0.13)$ \\
Shadow rate as base-country rate only/for all AE local economies & $0.90(0.00)$ & $0.85(0.00)$ & $0.70(0.00)$ & $0.45(0.01)$ \\
Shadow rates only for base-countries & $0.65(0.00)$ & $0.61(0.00)$ & $0.19(0.23)$ & $0.20(0.15)$ \\
\hline \hline$p$-values in parentheses & & & &
\end{tabular}

Driscoll-Kraay robust standard errors.

Next, recall that shadow rates that may reflect better the overall monetary policy stance when a central bank hits its effective lower bound are not available for all local economies in our sample. In our baseline, we therefore use conventional policy rates for the base-country when there is no shadow rate for a local economy that hit the effective lower bound. Row (3) in Table 20 reports the results from regressions in which we use the conventional policy rate in case of both base-countries as well as all local economies. In row (4) we report results from regressions in which we use the shadow rate for the base-countries in case of all local economies. Row (5) reports results from regressions in which we use the base-country shadow rate in case of all local AEs rather than only in case of the UK and Japan. And finally, row (6) reports results from regressions in which we use shadow rates only for base-countries, but not for the UK and Japan. The results are overall similar to those from the baseline. 


\section{E.4 Alternative Taylor-rule specification}

We explore three sets of alternative specifications of the Taylor rule. First, we explore different definitions of the variables included in the baseline specification. In particular, we consider the possibility that the timing of the surveys on which the CE forecast data are based do not coincide with the point in time at which the central projections are constructed. In this case, it might be that the $\mathrm{CE}$ forecasts build on more/less information than central banks actually had at the time when constructing the projection. To address this possibility, we replace the period- $t$ twelve-months ahead forecasts of GDP growth and inflation from CE by their one-period lags or leads. The results are reported in rows (2) and (3) in Table 21 and are consistent with those from the baseline.

Table 21: Alternative Taylor-rule specification

\begin{tabular}{|c|c|c|c|c|}
\hline & $\begin{array}{l}\text { (1) } \\
\text { Lim. FX flex. } \\
\text { \& Lim. CCs }\end{array}$ & $\begin{array}{l}\text { Lim. } \stackrel{(2)}{\text { FX flex. }} \\
\text { \& Ext. CCs }\end{array}$ & $\begin{array}{l}\text { (3) } \\
\text { Ext. } \stackrel{\text { FX flex. }}{ } \\
\text { \& Lim. CCs }\end{array}$ & $\begin{array}{l}\text { (4) } \\
\text { Ext. } \stackrel{\text { FX flex. }}{\text { \& Ext. CCs }}\end{array}$ \\
\hline Baseline & $0.76(0.00)$ & $0.61(0.00)$ & $0.45(0.02)$ & $0.20(0.15)$ \\
\hline Lagged period- $t$ forecasts & $0.77(0.00)$ & $0.66(0.00)$ & $0.41(0.10)$ & $0.22(0.27)$ \\
\hline Lead period- $t$ forecasts & $0.73(0.00)$ & $0.55(0.00)$ & $0.33(0.15)$ & $0.17(0.36)$ \\
\hline Quarterly frequency & $0.23(0.00)$ & $0.15(0.00)$ & $0.17(0.00)$ & $0.09(0.00)$ \\
\hline Add REER & $0.86(0.00)$ & $0.48(0.00)$ & $0.45(0.06)$ & $-0.06(0.77)$ \\
\hline No global variables & $0.81(0.00)$ & $0.63(0.00)$ & $0.47(0.01)$ & $0.20(0.18)$ \\
\hline
\end{tabular}

Second, some central banks do not hold their monetary policy decision meetings at the monthly frequency, so that estimating a Taylor rule with monthly data might not be appropriate. We therefore also estimate the Taylor rules at quarterly frequency on temporally aggregated data. The results are reported in row (4) in Table 21, and are consistent with those from the baseline.

Third, rows (5) and (6) report results from regressions in which we add the logarithm of the real effective exchange rate and in which we remove the global variables, respectively. The results are consistent with those from the baseline.

\section{E.5 Uncovered interest rate parity approach}

Shambaugh (2004), Obstfeld et al. (2005) as well as Klein and Shambaugh (2015) consider regressions based on the uncovered interest rate parity (UIP) condition given by

$$
\Delta i_{i t}=\vartheta_{j}+\delta_{j} \cdot \Delta i_{b_{i}, t}+\mu_{i t},
$$

instead of Taylor rules in order to assess the empirical validity of the trilemma. The UIP-based regressions are typically run using money-market instead of policy rates. The structure the UIP-based regressions impose on the data is minimal, which has advantages and disadvantages over the Taylor-rule regressions we consider in this paper. Specifically, one advantage is that 
the UIP-based approach does not require that local monetary policy is based on a Taylor rule with identical functional form, parameter values and arguments across local economies. The UIP-based approach therefore limits the potential for heterogeneity bias. In contrast, a disadvantage of the UIP-based approach is that the error term $\mu_{i t}$ may include components that are correlated with the base-country policy rate, which could in general bias the estimate of $\delta_{j}$ (Klein and Shambaugh, 2015). Moreover, the UIP-based approach does not imply to include any controls in the regression, so that the fit and thus the precision of the estimates may be poor.

Table 22 reports the estimates of $\delta_{j}$ from Equation (E.3) from various UIP-based regressions. In particular, row (2) in Table 22 reports results from the estimation of Equation (E.3) on the same time series and country sample as in our baseline. Given that in the UIP-based approach we do not require data on controls such as the CE forecasts, we can estimate them for a larger set of economies than the Taylor rule in Equation (4). The results are reported in row (3). And rows (4) and (5) report results from using short-term - typically three-month - moneymarket rates rather than policy rates. Overall, the results from the UIP-based regressions are consistent with those from the Taylor-rule approach in our baseline. However, as one would expect given the minimal structure imposed on the data, the estimates obtained from the UIP-based regressions are less precise than those obtained from the Taylor-rule approach in our baseline. Finally, notice the similarity between the findings we obtain based on the UIP approach in this paper and those by Klein and Shambaugh (2015), in particular when we consider the full set of countries for which we have data (rows (3) and (5)): Flexible exchange rates appear to have a greater potential to mitigate spillovers from base-country to local monetary policy than capital controls.

Table 22: UIP-based regressions

\begin{tabular}{|c|c|c|c|c|}
\hline & $\begin{array}{l}\text { (1) } \\
\text { Lim. FX flex. } \\
\text { \& Lim. CCs }\end{array}$ & $\begin{array}{l}\text { (2) } \\
\text { Lim. } \stackrel{\text { FX flex. }}{\text { \& Ext. CCs }}\end{array}$ & $\begin{array}{l}\text { (3) } \\
\text { Ext. } \stackrel{\text { FX flex. }}{\text { \& Lim. CCs }}\end{array}$ & $\begin{array}{l}\text { (4) } \\
\text { Ext. } \stackrel{\text { FX flex. }}{ } \\
\text { \& Ext. CCs }\end{array}$ \\
\hline Baseline & $0.76(0.00)$ & $0.61(0.00)$ & $0.45(0.02)$ & $0.20(0.15)$ \\
\hline UIP & $0.21(0.00)$ & $0.22(0.00)$ & $0.07(0.25)$ & $0.02(0.78)$ \\
\hline UIP with full $N$ & $0.19(0.00)$ & $0.15(0.01)$ & $0.04(0.64)$ & $-0.02(0.80)$ \\
\hline UIP money-market rate & $0.38(0.01)$ & $0.71(0.01)$ & $-0.40(0.41)$ & $0.46(0.02)$ \\
\hline UIP money-market rate with full $N$ & $0.49(0.00)$ & $0.32(0.06)$ & $0.07(0.88)$ & $0.33(0.21)$ \\
\hline
\end{tabular}

